\title{
Chronic dietary toxicity and carcinogenicity studies of dammar resin in F344 rats
}

Min Gi, Masaki Fujioka, Shotaro Yamano, Anna Kakehashi, Yuji Oishi, Takahiro Okuno, Nao Yukimatsu, Takashi Yamaguchi, Yoshiyuki Tago, Mistuaki Kitano, Shim־mo Hayashi, Hideki Wanibuchi

\begin{tabular}{|c|l|}
\hline Citation & Archives of Toxicology, 92(12); 3565-3583 \\
\hline Issue Date & $2018-12$ \\
\hline Type & Journal Article \\
\hline Textversion & Author \\
\hline $\begin{array}{c}\text { Electronic } \\
\text { supplementary } \\
\text { material }\end{array}$ & $\begin{array}{l}\text { Electronic supplementary material is available at } \\
\text { https://doi.org/10.1007/s00204-018-2316-7. }\end{array}$ \\
\hline Rights & $\begin{array}{l}\text { This is a post-peer-review, pre-copyedit version of an article published in Archives of } \\
\text { Toxicology. The final authenticated version is available online at: } \\
\text { https://doi.org/10.1007/s00204-018-2316-7 }\end{array}$ \\
\hline DOI & $10.1007 /$ s00204-018-2316-7 \\
\hline
\end{tabular}

Self-Archiving by Author(s) Placed on: Osaka City University 
Chronic Dietary Toxicity and Carcinogenicity Studies of Dammar Resin in F344 Rats

Min $\mathrm{Gi}^{1}$, Masaki Fujioka ${ }^{1}$, Shotaro Yamano ${ }^{1,2}$, Anna Kakehashi ${ }^{1}$, Yuji Oishi ${ }^{1}$, Takahiro Okuno $^{1}$, Nao Yukimatsu ${ }^{1}$, Takashi Yamaguchi ${ }^{1}$, Yoshiyuki Tago $^{1}$, Mistuaki Kitano ${ }^{1}$, Shim-mo Hayashi ${ }^{3}$, Hideki Wanibuchi ${ }^{1, *}$

${ }^{1}$ Department of Molecular Pathology, Osaka City University Graduate School of Medicine, 1-4-3 Asahi-machi, Abeno-ku, Osaka 545-8585, Japan.

${ }^{2}$ Present address: Japan Bioassay Research Center, Japan Organization of Occupational Health and Safety, Hadano, Kanagawa 257-0015, Japan

${ }^{3}$ Global Scientific and Regulatory Affairs, San-Ei Gen F.F.I., Inc., 1-1-11 Sanwa-cho, Toyonaka, Osaka 561-8588, Japan.

*To whom correspondence should be addressed: Tel: +81 6-6645-3735; Fax: 81-66646-3093; E-mail: wani@med.osaka-cu.ac.jp.

Running title: Dammar resin is a hepatocarcinogen in rats

Keywords: Dammar resin; Food additive; Liver tumor; Hepatocarcinogen; Male F344 rats; Hemorrhagic diathesis. 


\section{Abstract}

Dammar resin is a natural food additive and flavoring substance present in many foods and drinks. The present study evaluates the chronic toxicity and carcinogenicity of dietary dammar resin in F344 rats. Dietary concentrations in the 52 weeks chronic toxicity study were $0,0.03,0.125,0.5$, or $2 \%$. The major treatment-related deleterious effects were body weight suppression, increased relative liver weight, and low hemoglobin levels in males and females. Foci of cellular alteration in the liver were observed in the male $2 \%$ group, but not in any other group. The no-observed-adverse-effect level for chronic toxicity was $0.125 \%$ for males (200.4 mg/kg b.w./day) and females (241.9 mg/kg b.w./day). Dietary concentrations in the 104-week carcinogenicity study were $0,0.03,0.5$, or $2 \%$. Dammar resin induced hemorrhagic diathesis in males and females, possibly via inhibition of extrinsic and intrinsic coagulation pathways. Incidences of hepatocellular adenomas and carcinomas were significantly increased in the male $2 \%$ group, but not in any other group. In the 4-week subacute toxicity study, the livers of male rats fed diets containing $2 \%$ dammar resin had increased levels of protein oxidation and increased expression of two anti-apoptotic and seven cytochrome P450 (CYP) genes. There was also an increased tendency of oxidative DNA damage. These findings demonstrate that dammar resin is hepatocarcinogenic in male F344 rats and underlines the roles of inhibition of apoptosis, induction of CYP enzymes, and oxidative stress in dammar resin-induced hepatocarcinogenesis. 


\section{Introduction}

Dammar resin is the dried exudate from trees of the Agathis, Hopea, or Shorea genera. It consists of a complex of acidic and neutral terpenoid compounds together with polysaccharides, and is used as a natural food additive (stabilizer, glazing agent, and clouding agent) and flavoring substance in many foods and drinks, including beverages, frozen desserts, and chewing gum (Cohen et al. 2017; JECFA 1986; USP 2012).

There are several in vitro studies showing beneficial effects of dammar resin including antiviral activities (Poehland et al. 1987) and inhibition of low-density lipoprotein oxidation (Andrikopoulos et al. 2003). Terpenoids isolated from dammar resin showed cytotoxic activity against human leukemia and melanoma cells (Ukiya et al. 2010). In contrast, we recently reported the results of a 14-week study using gpt delta mice in which dammar resin induced oxidative DNA damage in the livers of these mice and increased liver cell proliferation activity and liver weight; although dammar resinassociated mutagenicity was not observed (Xie et al. 2012). Considering dammar resin induced DNA damage in liver cells and the likelihood of long-term ingestion of this food additive, it is necessary to identify the potential hazardous properties of repeated exposure to dammar resin over a prolonged period of time. Currently, no studies on the effects of long-term dietary intake of dammar resin have been reported, and therefore, there is no data on its chronic toxicity for establishment of acceptable daily intake levels.

The purpose of the present study was to determine the chronic toxicity and carcinogenicity of dietary dammar resin in a 52-week chronic toxicity and a 104-week carcinogenicity study in F344 rats. These bioassays demonstrated that dammar resin is carcinogenic to the liver in male rats and induced anemia and coagulation disorders in 
male and female rats. We also examined the effects of the carcinogenic concentration of dammar resin on cell proliferation, apoptosis, induction of oxidative stress, and cytochrome P450 (CYP) enzymes in the livers of male rats in a 4-week subacute toxicity study. 


\section{Materials and methods}

\section{Test chemical and diets}

Dammar resin powder (CAS No. 9000-16-2) (geographical origin: Sumatra, Malaysia) was provided by San-Ei Gen F.F.I., Inc., Osaka, Japan. Basal diet (MF powder diet, Oriental Yeast Co., Ltd., Tokyo, Japan) and diets supplemented with different doses of dammar resin were prepared and pelleted by Oriental Yeast Co., Ltd., and used within 4 weeks of preparation. The stability and homogeneity of dammar resin in dietary mixtures were analyzed using an Agilent Technologies 6890N Gas Chromatograph System at SanEi Gen F.F.I., Inc., Japan, and the results showed that all dose formulations were stable and homogenous for at least 6 weeks at room temperature.

\section{Animals and husbandry}

All animal studies were approved by the Institutional Animal Care and Use Committee of Osaka City University Graduate School of Medicine and conducted in accordance with the Guidelines for Proper Conduct of Animal Experiments (Science Council of Japan, 2006). The Laboratory Animal Center of Osaka City University Graduate School of medicine is accredited by the Center for the Accreditation of Laboratory Animal Care and Use (CALAC), Japan Health Sciences Foundation (JHSF). Five-week old male and female F344/DuCrlCrlj rats were obtained from Charles River Japan, Inc. (Atsugi, Kanagawa, Japan). Rats were housed in polycarbonate cages with wood chips for bedding in experimental animal rooms at a temperature of $22 \pm 3^{\circ} \mathrm{C}$, a relative humidity of $55 \pm$ 5\%, and a 12-h light/dark cycle. Rats were used after a 7-day acclimatization period and were 6 weeks old at the beginning of the study. Fresh diet and tap water were supplied to 
rats once weekly and were available ad libitum throughout the study. Body weight and food and water consumption were measured weekly in the 4-week subacute toxicity study and measured weekly until week 13 and every 4 weeks thereafter in the chronic toxicity and carcinogenicity studies.

\section{Subacute toxicity study}

To determine the maximum dose for the chronic toxicity and carcinogenicity studies, groups of 10 male and 10 female F344 rats were fed diets supplemented with 0, 2, or 5\% dammar resin for 4 weeks. The dose of $5 \%$ was selected in accordance with the following Guideline for Assessment of the Effect of Food on Human Health Regarding Food Additives, Ministry of Health Labour and Welfare, Japan: The ratio of the substance to the feed does not have to exceed $5 \%$ when the substance is administered by feeding because of the possibility that higher levels will cause nutritional imbalance (FSCJ 2010).

At the end of 4 weeks, rats were fasted overnight, euthanized by inhalation of an overdose of isoflurane (Abbott Japan Co., Ltd., Tokyo, Japan) using a Small Animal Anesthetizer (MK-A110D, Muromachi Kikai Co., LTD., Tokyo, Japan) coupled with an Anesthetic Gas Scavenging System (MK-T 100E, Muromachi Kikai Co., LTD., Tokyo, Japan). At necropsy, livers were excised and weighed. A total of 3 sections of liver tissue (one section each from the left lateral lobe, right middle lobe, and caudate lobe) were fixed in $10 \%$ neutral phosphate buffered formalin, embedded in paraffin, sectioned at 4 $\mu \mathrm{m}$, and stained with hematoxylin and eosin for histopathological analysis. The remaining liver tissues were snap frozen with liquid nitrogen and stored at $-80{ }^{\circ} \mathrm{C}$ for detection of protein oxidation and oxidative DNA damage and for mRNA expression analysis. 


\section{Chronic toxicity and carcinogenicity studies}

In the chronic toxicity study, groups of 10 male and 10 female rats were fed diets supplemented with $0,0.03,0.125,0.5$ or $2 \%$ dammar resin for 52 weeks. In the carcinogenicity study, groups of 50 male and 50 female rats were fed diets supplemented with $0,0.03,0.5$, or $2 \%$ dammar resin for 104 weeks. The highest dose of $2 \%$ was determined based on the results of the above 4 -week subacute toxicity study: the $5 \%$ dose caused significant body weight depression in both male and female rats, and in male rats the body weight was decreased by more than $15 \%$ relative to controls (described in the Results).

Rats were euthanized after 52 weeks of treatment in the chronic toxicity study and after 104 weeks of treatment in the carcinogenicity study, and complete macroscopic and histopathological examinations were performed. Rats that had died or were euthanized when becoming moribund during the study were also completely necropsied and macroscopic and histopathological examinations were performed. For rats necropsied at the end of the study, liver, kidneys, spleen, thymus, heart, brain, and testes (males) were excised and weighed. The salivary glands, thymus, trachea, lungs, heart, parathyroid and thyroid, tongue, esophagus, fore-stomach, glandular stomach, small intestine (duodenum, jejunum, ileum), large intestine (cecum, colon, rectum), liver, pancreas, spleen, kidneys, adrenal glands, urinary bladder, seminal vesicles, prostate, testes, epididymis, ovaries and fallopian tubes, uterus, vagina, brain, pituitary gland, sternum, chest bone, femur (including joints), nasal cavity, sciatic nerve, femoral muscle, spinal cord, intrathoracic aorta, eyeballs and Harderian gland, skin, Zymbal's gland, mammary tissue, lymph nodes (cervical and mesenteric), and all macroscopically abnormal sites were fixed and 
preserved in $10 \%$ neutral buffered formalin except for testes which were fixed in Bouin's solution. Bones were decalcified in 5\% NaSO4 Plank-Rychlo solution overnight. After fixation, organs and tissues were processed and trimmed, embedded in paraffin, sectioned at $4 \mu \mathrm{m}$, and stained with hematoxylin and eosin for histopathological analysis. In the chronic toxicity study, foci of cellular alteration were examined in 3 tissue sections from each of the left lateral lobe, right middle lobe, and caudate lobe of the livers. In the carcinogenicity study, neoplastic lesions were examined from tissue sections from macroscopic lesions and 3 tissue sections from each of the normal-like left lateral lobe, right middle lobe, and caudate lobe of the livers.

Histopathologic examinations were conducted by three pathologists certified by the Japanese Society of Toxicologic Pathology (Gin M., Oishi Y., and Wanibuchi H.) in accordance with INHAND: International Harmonization of Nomenclature and Diagnostic Criteria for Lesions in Rats and Mice (INHAND).

\section{Hematology, clinical chemistry, and urinalyses}

At necropsy of the chronic toxicity and carcinogenicity studies, whole blood samples were collected via the abdominal aorta under anesthesia after overnight fasting. Hematology and serum biochemical parameters were measured in all rats (10 rats/sex/group) in the chronic toxicity study at LSI Medience Corporation, Tokyo, Japan. The hematological parameters examined were white blood cell (WBC) count, red blood cell (RBC) count, hemoglobin concentration $(\mathrm{Hb})$, hematocrit $(\mathrm{Ht})$, mean corpuscular volume $(\mathrm{MCV})$, mean corpuscular hemoglobin $(\mathrm{MCH})$, mean corpuscular hemoglobin concentration (MCHC), and platelet (Plt) count. The serum biochemical parameters examined were aspartate aminotransferase (AST), alanine aminotransferase (ALT), 
alkaline phosphatase (ALP), gamma-glutamyl transpeptidase (gamma-GTP), total protein (TP), albumin (ALB), albumin/globulin ratio (A/G ratio), triglycerides (TG), total cholesterol (T-cho), creatinine, blood urea nitrogen $(B U N)$, sodium $(N)$, potassium $(K)$, chloride $(\mathrm{Cl})$, calcium $(\mathrm{Ca})$, and phosphorus $(\mathrm{P})$.

Since hemorrhagic diathesis was observed in several rats that died or were found in a moribund state during the carcinogenicity study, both hematology parameters and the coagulation factors prothrombin time (PT) and activated partial prothrombin time (APTT) were measured in at least 7 rats without gross abnormalities in each group, except for the male $2 \%$ group of the carcinogenicity study due to technical issues during necropsy.

Urinalysis was conducted for all animals in the chronic toxicity study at week 52 . Urine was collected by forced urination between 0800 am $1000 \mathrm{am}$, and measured immediately for $\mathrm{pH}$, protein, glucose, ketone, specific gravity, occult blood, WBC (leukocyte esterase test), bilirubin, urobilinogen, and nitrite using test paper N-Siemens N-Multistix ${ }^{\circledR}$ SG-L Urinalysis Test Strips with a Clinitek Status ${ }^{\circledR}$ Urine Analyzer (Bayer Health Care LLC, NY, USA).

\section{Detection of protein oxidation and oxidative DNA damage in the livers of the rats in}

\section{the 4-week subacute toxicity study}

Protein carbonyl content, a marker of protein oxidation, was examined in 6 rats per group in the male control and $2 \%$ dammar resin groups using a Protein Carbonyl Colorimetric Assay (Cayman Chemical Company, MI, USA) according to the manufacture's protocol.

8-OHdG in liver DNA, a marker of oxidative DNA damage (Dizdaroglu et al. 2002), was determined in 10 rats in the male control and $2 \%$ dammar resin groups by high- 
performance liquid chromatography with electrochemical detection as described previously (Fukushima et al. 2002).

\section{mRNA expression analysis in livers in the 4-week subacute toxicity study}

Total RNA was isolated from frozen liver tissue of 6 male rats per group from the control and $2 \%$ groups using TRIzol ${ }^{\circledR}$ Reagent (Life Technologies, Gaithersburg, MD, USA) according to the manufacturer's instructions. cDNA synthesis was performed with $1 \mu \mathrm{g}$ of RNA using an Advantage RT-for-PCR kit (Takara Bio, Inc., Otsu, Japan). The mRNA expression levels of genes involved in cell proliferation (proliferating cell nuclear antigen [PCNA]), cell cycle regulation (p53 and $\left.\mathrm{p} 21^{\mathrm{Cip} / \mathrm{WAF} 1}\right)$, apoptosis (BCL2, myeloid cell leukemia 1 [Mcl-1]), nucleolar protein 3 (NOL3, also known as Apoptosis Repressor with CARD Domain), survivin, p53 upregulated modulator of apoptosis (PUMA), and BAX (BCL2-associated X protein), and 14 cytochrome P450 enzymes in families CYP1-4 were determined by TaqMan real-time quantitative PCR. PCR reagents and sequence-specific primers and probes for each gene (Taqman Gene Expression Assay) were purchased from Applied Biosystems, Inc., CA, USA. mRNA expression assays were performed using a 7500 Fast Real-Time PCR System (Applied Biosystems, Inc., CA, USA). ß-actin was employed as an internal control. Serially diluted standard cDNAs were included in each Taqman PCR reaction to create standard curves. The amounts of gene products in the test samples were estimated relative to the respective standard curves. Values for target genes were normalized to those for $\beta$-actin. 


\section{Statistics}

All mean values are reported as mean \pm SD. Statistical analyses, except for Poly-k test, were performed using Prism 7 for Mac OS X (GraphPad Software, Inc., San Diego, CA, USA). Homogeneity of variance was tested by the F-test or Bartlett test. Differences in mean values between the control and treated groups in the 52-week chronic toxicity and the 104-week carcinogenicity studies were evaluated by the Dunnett's Multiple Comparison Test when variance was homogeneous or the Dunn's test when variance was heterogeneous (multi-group comparisons). Differences in mean values of mRNA expression, $8-\mathrm{OHdG}$, and protein carbonyl content between the control and the $2 \%$ male groups were evaluated by 2-tailed Student's t-test when variance was homogeneous and 2-tailed Welch's t-test when variance was heterogeneous in the 4-week subacute study (two-group comparisons). The Kaplan-Meir method and log-rank test was used for survival analysis. Incidences of neoplastic lesions were analyzed for a dose-response relationship by the Poly-k $(\mathrm{k}=3)$ test (Poly-3 trend test) using the age-adjusted Poly-k testing software available at https://www.jstatsoft.org/article/view/v016i07 (Moon et al. 2006). Differences in the incidences of histopathological lesions and urinalysis parameters between control and treatment groups were evaluated by 2-tailed Fisher's exact test. $p$ values less than 0.05 were considered significant. 


\section{Results}

\section{Subacute toxicity study: Determination of the maximum dose for the chronic toxicity and carcinogenicity studies}

Survival, final body weights, liver weights, and water intake and food consumption are summarized in Table 1. Final body weights were significantly decreased in males in the $2 \%$ and $5 \%$ groups and females in the $5 \%$ group compared to their respective controls. Absolute liver weights were significantly increased in males in the 5\% group and in females in the $2 \%$ and $5 \%$ groups. Relative liver weights were significantly increased in males and females in the $2 \%$ and $5 \%$ groups. Centrilobular hypertrophy was observed in males in the $2 \%$ and $5 \%$ groups but not in either the $2 \%$ or $5 \%$ female groups. Based on the results that the final body weights of both sexes were significantly decreased in rats fed the $5 \%$ dammar resin supplemented diet, despite increased food consumption, and that the decrease in the males was more than $15 \%$ relative to the controls, the highest dose for the chronic toxicity and carcinogenicity studies was determined to be $2 \%$.

\section{Chronic toxicity study}

\subsection{General findings and organ weights}

Survival, final body weights, liver weights, water intake and food consumption, and dammar resin intake are summarized in Table 1. All animals survived to the end of the study. There were no treatment-related clinical findings in any of the groups. Decreased body weights were observed in males and females in the $2 \%$ groups, whereas increased body weights were observed in males in the $0.03 \%$ group and in females in the $0.03 \%$ and $0.125 \%$ groups (Fig. 1A, Supplementary Table 1). Final body weights were 
significantly decreased in males and tended to decrease in females in the $2 \%$ groups. In contrast, final body weights were significantly increased in males and females of the $0.03 \%$ group compared to their respective controls. Food consumption tended to increase in the male and female $0.03 \%, 0.125 \%$, and $0.5 \%$ groups compared to their respective control groups while it was comparable between the male and female $2 \%$ and control groups. Average intake of dammar resin in the $0.03 \%, 0.125 \%, 0.5 \%$, and $2 \%$ groups corresponded to $11.9,49.6,200.4$, and $856.7 \mathrm{mg} / \mathrm{kg}$ b.w./day in males, and 14.3, 59.2, 241.9, and $997.9 \mathrm{mg} / \mathrm{kg} \mathrm{b.w./day} \mathrm{in} \mathrm{females,} \mathrm{respectively,} \mathrm{and} \mathrm{was} \mathrm{approximately}$ proportional to the doses administered in the diet. Average water intake tended to increase in all the male treated groups and the female $2 \%$ group compared to their respective control groups.

Absolute liver weights were significantly increased in males and females in the $0.5 \%$ and $2 \%$ groups. Relative liver weights were significantly increased in males in the $2 \%$ group and in females in the $0.5 \%$ and $2 \%$ groups.

Weights of organs other than liver are summarized in Supplementary Table 2. Significant differences observed between the treated groups and the control group were as follows: decreased absolute spleen weights in both sexes in the $2 \%$ groups; increased absolute heart weight in males in the $0.03 \%$ group; increased relative heart, brain, and testes weights in males in the $2 \%$ group; decreased relative kidneys weights in females in the $0.03 \%, 0.125 \%$, and $0.5 \%$ groups; decreased relative brain weights in females in the $0.03 \%$ group; decreased relative heart weights in females in the $0.125 \%$ group. However, the alterations in organ weight were only observed either in their absolute or in their relative weight and were not dose-dependent; therefore, they are concluded to be the result of changes in body weight, lower body weights in the $2 \%$ groups and higher body 
weights in the lower dose groups compared to the control groups, and to lack toxicological significance.

\subsection{Hematological and serum biochemical findings}

Hematological and serum biochemical findings are summarized in Table 2. The findings that $\mathrm{Hb}$ levels were significantly decreased in males and females in the $0.5 \%$ and $2 \%$ groups indicate that dammar resin at doses of $0.5 \%$ and above induced anemia in both sexes. Slight but statistically significant alterations in anemia-related hematological parameters were as follows: decreased $\mathrm{RBC}$ number in males in the $2 \%$ group; increased $\mathrm{MCV}$ in males in the $2 \%$ group and females in the $0.5 \%$ and $2 \%$ groups; decreased $\mathrm{MCH}$ and $\mathrm{MCHC}$ in males and females in the $0.5 \%$ and $2 \%$ groups. Platelet numbers were significantly increased in males and females in the $0.5 \%$ and $2 \%$ groups. WBC numbers were significantly decreased in males in the $0.125 \%, 0.5 \%$, and $2 \%$ groups.

Serum biochemical parameters that showed significant differences between the treated groups and the control group in a dose-dependent manner and may have toxicological implication were as follows: increased gamma-GTP activities in females in the $0.5 \%$ and $2 \%$ groups; increased T-Cho concentrations in males in the $2 \%$ group and in females in the $0.5 \%$ and $2 \%$ groups; and decreased $\mathrm{A} / \mathrm{G}$ ratio in females in the $2 \%$ group. In addition, AST and ALT activities in males and females in the $0.5 \%$ and $2 \%$ groups and ALP activities and TG concentrations in males in the $0.5 \%$ and $2 \%$ groups were significantly decreased compared to their respective control groups; however, decreases in these parameters have not been shown to correlate with hepatotoxicity and usually are not considered to have toxicological implications (Hall et al. 2012). Other 
alterations were of minimal magnitude and/or were not dose-dependent, and therefore concluded to lack toxicological significance.

\subsection{Urinalysis}

Urinalysis data are summarized in Table 2. Incidences of proteinuria, over $300 \mathrm{mg} / \mathrm{dl}$, and increased leukocyte esterase to $3+$, which indicates an increase in WBC number, were significantly increased in males in the $2 \%$ group. There were no significant differences in other parameters between treated groups and their concurrent control groups (data not shown).

\subsection{Histopathological findings}

There were no treatment-related macroscopic findings at necropsy. Treatmentrelated histopathological findings in livers and kidneys are summarized in Table 3. There was no overt centrilobular hypertrophy or necrosis in the livers in any of the treated groups. Foci of cellular alteration in the liver were observed in 2 males in the $2 \%$ group but not in any other rats (Fig. 2A and B). Bile duct hyperplasia of the liver is a common aging lesion. Concordant with the significantly decreased activity of ALP in the males in the $2 \%$ group, the incidence of moderate bile duct hyperplasia $(3+)$ in the liver was significantly decreased in the male $2 \%$ group compared to the control group, and extensive bile duct hyperplasia (4+) was not observed in males in the $2 \%$ group while this lesion was observed in the other male groups including the control group. Concordant with the increased incidence of proteinuria over $300 \mathrm{mg} / \mathrm{dl}$ in males in the $2 \%$ group, incidences of rats with moderate proteinaceous cast $(3+)$ in their kidneys were significantly increased in the male $2 \%$ group. These findings indicate the possibility that 
dammar resin may injure the glomerular membrane, renal tubule, or both in male rats, though no histopathological abnormality was observed at the light microscopic level. There were no treatment-related histopathological findings in other organs and tissues. No tumors were observed in any group.

\section{Carcinogenicity study}

\subsection{General findings and organ weights}

Survival, final body weights, liver weights, water and food consumption, and dammar resin intake are summarized in Table 1 . The survival rates at the end of the carcinogenicity study were $43 / 50(86 \%), 41 / 50(82 \%), 40 / 50(80 \%)$, and $22 / 50(44 \%)$ in males in the control, $0.03 \%, 0.5 \%$, and $2 \%$ groups, respectively, and $37 / 50(74 \%), 43 / 50(86 \%), 46 / 50$ $(92 \%)$, and $42 / 50(84 \%)$ in females in the control, $0.03 \%, 0.5 \%$, and $2 \%$ groups, respectively. The survival rate of the male $2 \%$ group was significantly decreased compared to the control group (Fig. 3A). For female rats, there were no significant differences in survival rates between the control and treatment groups (Fig. 3B).

Decreased body weights were observed in the male and female $2 \%$ groups, whereas increased body weight was observed in males in the $0.03 \%$ group and in females in the $0.03 \%$ and $0.5 \%$ groups (Fig. 1B, Supplementary-Table 2). Final body weights were significantly decreased in the male and female $2 \%$ groups, but were significantly increased in the female $0.03 \%$ group.

The intake of dammar resin was approximately proportional to the doses administered in the diet; although, average food consumption in the male $0.03 \%, 0.5 \%$, and $2 \%$ groups and in the female $0.03 \%$ and $0.5 \%$ groups tended to increase compared to their respective control groups. Average intake of dammar resin in the $0.03 \%, 0.5 \%$, and 
$2 \%$ groups corresponded to $10.5,178.3$, and $766.9 \mathrm{mg} / \mathrm{kg} \mathrm{b.w./day} \mathrm{in} \mathrm{male} \mathrm{rats} \mathrm{and} 12.2$, 205.4, and $868.1 \mathrm{mg} / \mathrm{kg} \mathrm{b.w./day} \mathrm{in} \mathrm{female} \mathrm{rats,} \mathrm{respectively.} \mathrm{Average} \mathrm{water} \mathrm{intake}$ tended to increase in the male $0.03 \%, 0.5 \%$, and $2 \%$ groups compared to the control group, but were similar between the female control and treated groups.

Absolute and relative liver weights were significantly increased in males in the $0.03 \%, 0.5 \%$, and $2 \%$ groups, and in females in the $0.5 \%$ and $2 \%$ groups in a dosedependent manner. Absolute, but not relative liver weights, were significantly increased in females in the $0.03 \%$ group, possibly due to the significantly increased body weights. Other significant differences in organ weights between the control groups and treatment groups were noted in kidneys, spleen, heart, and brain (Supplementary-Table 3). However, the alterations in organ weight, other than liver, were only observed either in their absolute or in their relative weight and were not dose-dependent; therefore, they are concluded to be the result of changes in body weight and to lack toxicological significance.

\subsection{Increased susceptibility to hemorrhage}

Hemorrhagic diathesis in the form of gross gastrointestinal and genitourinary hemorrhage was observed in males and females in the $0.5 \%$ and $2 \%$ groups from week 87 , and was especially evident in male rats in the $2 \%$ group. The incidences of hemorrhagic diathesis in rats that died or were euthanized before the termination of the study were $2 / 10(20 \%)$ and $13 / 28(46.4 \%)$ in males in the $0.5 \%$ and $2 \%$ groups, respectively, and $1 / 4(25 \%)$ and $4 / 8(50 \%)$ in females in the $0.5 \%$ and $2 \%$ groups, respectively. Therefore, hemorrhagic diathesis was a major cause of death in the male and female $2 \%$ groups. The total incidences of hemorrhagic diathesis were $4 / 50(8 \%)$ and $33 / 50(66 \%)$ in the $0.5 \%$ and $2 \%$ male groups respectively, and $1 / 50(2 \%)$ and $8 / 50(16 \%)$ in the $0.5 \%$ and $2 \%$ female 
groups, respectively. No hemorrhagic diathesis was observed in rats of the control or $0.03 \%$ groups. The total incidence of hemorrhagic diathesis was significantly increased in the male and female $2 \%$ groups compared to their respective control groups, and was significantly increased in the male $2 \%$ group compared to the female $2 \%$ group.

\subsection{Hematology and coagulation test}

The results of hematology and coagulation factor analyses are summarized in Table 4. $\mathrm{Hb}$ levels, $\mathrm{RBC}$ number, hematocrit, $\mathrm{MCH}$, and $\mathrm{MCHC}$ were significantly decreased in males in the $2 \%$ group compared to the controls. In females in the $2 \%$ group, Hb levels tended to decrease, and $\mathrm{MCH}$ and $\mathrm{MCHC}$ were significantly decreased compared to the controls. Platelet numbers were significantly increased in the male and female $2 \%$ groups. There were no significant changes in the above parameters in male or female rats fed diets supplemented with $0.5 \%$ or $0.03 \%$ dammar resin. PT and APTT were measured as activation markers of extrinsic and intrinsic coagulation pathways, respectively. Significantly prolonged PT and APTT were observed in males in the $0.5 \%$ group. PT and APTT were not examined in the male $2 \%$ group due to technical problems at necropsy. In the female $2 \%$ group, PT and APTT showed a tendency to be prolonged. These results suggest that dammar resin at doses of $2 \%$ induced anemia and inhibited extrinsic and intrinsic coagulation pathways in male rats in the carcinogenicity study. Similar, but milder, toxic effects were also observed in the female $2 \%$ group. These results suggest that dammar resin inhibited both the extrinsic and intrinsic coagulation pathways, and consequently induced anemia and hemorrhagic diathesis in rats in the high dose groups. 


\subsection{Histopathologic findings}

The incidences of hepatocellular adenomas and carcinomas in the male control, $0.03 \%$, $0.5 \%$, and $2 \%$ groups was $0 / 50,1 / 50,0 / 50$, and $11 / 50$ (adenomas), $0 / 50,0 / 50,0 / 50$, and 5/50 (carcinomas), and 0/50, 1/50, 0/50, and 15/50 (adenomas and/or carcinomas), respectively (Table 5; a hepatocellular carcinoma is shown in Figs. 2C and D). The incidences of hepatocellular adenomas, carcinomas, and total tumors (adenomas and/or carcinomas) were significantly increased in the male $2 \%$ group. The incidences of hepatocellular adenomas, carcinomas, and total tumors in the male $2 \%$ group also exceed the range of historical control incidences in male F344 rats from NTP studies $(0-6 \%$ and $0-4 \%$, respectively) (NTP 2011), indicating that the development of these tumors was increased by dammar resin administration. Furthermore, the multiplicity of hepatocellular adenomas, carcinomas, and total tumors was also significantly increased in the male $2 \%$ group.

The incidence and multiplicity of liver tumors in the females were not significantly different between the control group and the treatment groups (Table 5). Hepatocellular carcinoma occurred in one female in the $2 \%$ group; none occurred in the $0.03 \%, 0.5 \%$ or the control group. The Poly-k test suggested there was a positive dose-related trend in the incidence of hepatocellular carcinoma in female rats, but the increase was not statistically significant and the incidence in the $2 \%$ group falls within the range of historical control incidences for female F344 rats from NTP studies (0 - 2\%) (NTP 2011). Consequently, the marginal increase in hepatocellular carcinoma in female rats was not considered related to dammar resin administration. The incidence and multiplicity of liver tumors in the females were not significantly different between the control group and the treatment groups (Table 5). 
Neoplastic lesions in organs and tissues other than the liver are summarized in Table 6. Adenocarcinoma of jejunum occurred in one male in the $2 \%$ group; adenoma of lung occurred in one female in the $2 \%$ group; adenoma of colon occurred in one female in the $2 \%$ group, none of the above tumors occurred in the respective $0.03 \%, 0.5 \%$ or the control group. Incidences of these tumors showed a positive dose-related trend. However, these increases were not statistically significant from the respective control group, and the incidences in the $2 \%$ group fall within the range of historical control incidences for F344 rats from NTP studies (adenocarcinoma of jejunum in male rats: 0 - 2\%; adenoma of lung in female rats: 0 - 8\%; adenoma of colon in female rats: 0 - 2\%, respectively) (NTP 2011). Therefore, the marginal increases in the above tumors were not considered related to dammar resin administration. There was a significant decrease in the incidence of pancreatic islet cell adenomas, testicular interstitial cell tumors, and skin/subcutaneous fibromas in the male $2 \%$ group, possibly due to the high mortality rate and corresponding early death of these animals. In addition, in the female $2 \%$ group, there was a statistically significant decrease in the incidence of pituitary adenoma and total pituitary tumors (adenoma and adenocarcinoma) compared to the control group.

Histopathologically, hemorrhagic diathesis was characterized by the presence of red blood cells in tissues and/or lumina of multiple organs including the gastrointestinal tract (stomach, duodenum, jejunum, ileum, cecum, colon, and rectum), urinary bladder, prostate, testis, epididymis, heart, lung, and subcutis. The organs with hemorrhage and degrees of hemorrhage varied from rat to rat even in the same treatment group. Histopathologically, the most marked hemorrhage was observed in the urinary bladders (Supplementary Fig.1A) and prostate (Supplementary Fig.1B), characterized by the 
presence of hemorrhagic masses in the interstitial spaces, and in some instances was accompanied by disintegration of the normal structures owing to necrosis and being suffused with blood. Although the presence of gross luminal hemorrhage in the gastrointestinal tract was observed in all rats diagnosed with hemorrhagic diathesis, red blood cells were not evident microscopically in the tissue sections of some rats, possibly due to the fact that they may have been washed out during tissue preparation, and not all the areas of the gastrointestinal tract were examined. The presence of red blood cells in the gastrointestinal tract was generally observed in the lamina propria of the epithelium, and in some instances was accompanied by the presence of macrophages with intracellular phagocytosed debris.

\section{Subacute toxicity study: Effect of diets supplemented with $2 \%$ dammar resin (the hepatocarcinogenic dose) on the livers of male rats}

\section{1 mRNA expression of genes involved in cell proliferation, cell cycle regulation, apoptosis, and CYPs in the liver}

There were no significant differences in the mRNA levels of PCNA (Fig. 4A), p53, or $\mathrm{p} 21^{\mathrm{Cip} / \mathrm{WAF} 1}$ (data not shown) in the livers of males fed $2 \%$ dammar resin and their controls. The expression of the anti-apoptotic genes Bcl2 and NOL3, was significantly increased in the livers of males fed $2 \%$ dammar resin compared to the controls (Fig. 4B). There were no significant alterations in the expression of the anti-apoptotic genes Mcl-1 and Survivin, or the pro-apoptotic genes BAX and PUMA (data not shown).

Hepatic mRNA expression of CYP1A1, CYP2B1, CYP2B2, CYP2C6, CYP2E1, CYP3A1, and CYP3A2 was significantly increased by administration of $2 \%$ dammar 
resin in male rats compared to the controls, while the expression of CYP4A1 and CYP4A2 was significantly decreased (Fig. 4C). Dammar resin had no effect on the mRNA levels of CYP1B1, CYP2A1, CYP2A2, CYP2C7, or CYP2C11 (data not shown).

\subsection{Protein oxidation and oxidative DNA damage}

Protein carbonyl content in the liver was significantly increased in males fed $2 \%$ dammar resin compared with the controls, indicating increased protein oxidation (Fig. 4D). 8OHdG tended to be increased in males fed $2 \%$ dammar resin compared with the controls, albeit without statistical significance (Fig. 4D). 


\section{Discussion}

In the carcinogenicity study, the incidences of both hepatocellular adenoma and carcinoma were significantly increased in the male $2 \%$ group compared with the control group. Furthermore, the multiplicities of hepatocellular adenoma and carcinoma in the male $2 \%$ group were significantly increased compared with the control group. These findings clearly demonstrate that dammar resin is hepatocarcinogenic in male F344 rats.

Dammar resin was negative in a variety of genotoxicity assays including mutagenicity assays with prokaryotic organisms, the in vitro chromosomal aberration test in CHL/IU cells, and the in vivo mouse bone marrow micronucleus assay (Hayashi et al. 2000). We have recently demonstrated that dammar resin was negative in in vivo mutagenicity assays in the livers of gpt delta mice (Xie et al. 2012) and gpt delta rats (manuscript in preparation). These results suggest that dammar resin is a non-genotoxic hepatocarcinogen in male rats. Several modes of actions have been proposed for nongenotoxic hepatocarcinogens in rodents including anti-apoptosis, oxidative stress, CYP enzyme induction, and nuclear receptor activation (Cohen 2010; Hall et al. 2012; Luch 2005). As cancer cells harbor stepwise accumulation of genetic alterations, it has been proposed that short-term studies determining early genetic alterations may provide useful information with respect to the mechanism by which chemicals induce tumors in rats (Cohen 2010; Kanki et al. 2016; Uehara et al. 2011; Yamada et al. 2013). We examined oxidative stress and the expression of CYP genes and genes involved in cell proliferation and apoptosis in the livers of male rats fed a diet supplemented with the carcinogenic dose $(2 \%)$ of dammar resin in a 4-week subacute toxicity study. We found that while dammar resin did not effect the expression of PCNA, p53, or p21 $1^{\mathrm{Cip} / \mathrm{WAF} 1}$, it significantly increased the level of expression of the anti-apoptotic genes Bcl-2 and NOL3. 2\% dammar resin 
also significantly increased the expression of 7 CYP isoforms (discussed below). Furthermore, protein oxidation was significantly increased and 8-OHdG in liver DNA, which is a well-known marker for oxidative DNA damage, was also increased, but without statistical significance. In our previous 14 -week study in gpt delta mice, $2 \%$ dammar resin significantly increased 8-OHdG in liver DNA (Xie et al. 2012), and 13 weeks dietary administration of $2 \%$ dammar resin significantly increased 8 -OHdG in liver DNA of male gpt delta rats (manuscript in preparation). The lack of statistical significance in $8-\mathrm{OHdG}$ in the present 4 -week study might be due to the short treatment duration. The above findings suggest that dammar resin induced hepatocarcinogenesis via suppression of apoptosis and induction of oxidative stress in rats.

CYP enzymes are responsible for the oxidative metabolism of many compounds into intermediates that can be further degraded or excreted; they are the primary enzymes responsible for the degradation and elimination of xenobiotics. However, oxidative metabolism catalyzed by CYP enzymes may result in continuous production of reactive oxygen species (ROS), and therefore has been suggested to be one of the major sources of ROS that induce oxidative stress (Zangar et al. 2004). ROS also serve as signaling molecules involved in redox biology, and these pathways participate in numerous cellular process, some of which can contribute to carcinogenesis (Nebert and Dalton 2006; Rodriguez-Antona and Ingelman-Sundberg 2006; Schieber and Chandel 2014). Dammar resin significantly increased expression of 7 CYP isoforms (CYP1A1, CYP2B1, CYP2B2, CYP2C6, CYP2E1, CYP3A1, and CYP3A2) in the livers of male rats in the 4-week subacute toxicity study, indicating that it is a CYP enzyme inducer and multiple CYPs might be involved in its metabolism. It is therefore reasonable to postulate that dammar 
resin activation of these CYP enzymes can lead to generation of ROS that consequently leads to protein oxidation and oxidative DNA damage.

A well-known pathway of CYP-mediated metabolism of their substrates is induction of expression by nuclear receptors. CYP1A1, CYP2Bs, and CYP3As are transcriptionally regulated by the nuclear transcription factors aryl hydrocarbon receptor, pregnane $\mathrm{X}$ receptor, and constitutive androstane receptor, respectively (Gibson et al. 2002; Luch 2005; Nebert and Dalton 2006; Tompkins and Wallace 2007). The finding that dammar resin increased mRNA levels of CYP1A1, CYP2Bs, and CYP3As suggest that dammar resin may contain ligands for multiple nuclear receptors in rats. On the other hand, dammar resin is not likely to be a PPAR $\alpha$ activator as there were no alterations in the expression of CYP4s.

For non-genotoxic carcinogens, a threshold dose below which no carcinogenic effect is produced is presumed to exist. In the present carcinogenicity study, a noobserved-adverse-effect level (NOAEL) was $0.5 \% \quad(178.3 \mathrm{mg} / \mathrm{kg} \quad$ b.w./day) for hepatocarcinogenicity in male rats as evidenced by the finding that a hepatocarcinogenic effect of dammar resin was observed at $2 \%$ but not $0.5 \%$. This also indicates that a doseresponse of hepatocarcinogenicity may exist between $0.5 \%$ and $2 \%$ in male rats. Furthermore, lack of hepatocarcinogenicity of dammar resin in female rats indicates that it is a male-specific rat hepatocarcinogen. Although the concentrations of dammar resin used as food additive are orders of magnitude lower than the hepatocarcinogenic dose in the present study, we have established that dammar resin is a hepatocarcinogen in rats and that its mechanism of action is likely to be relevant in humans. Further studies, such as whether dammar resin induces CYP enzyme expression and causes oxidative damage in human liver cells, are needed to clarify the role of metabolism and the precise 
mechanism of action of dammar resin in rat hepatocarcinogenesis. Clearly, the use of dammar resin as a food additive for humans should be carefully monitored.

In the chronic toxicity study, dammar resin at doses of $0.5 \%$ and $2 \%$ induced anemia, as evidenced by decreased hemoglobin level. In addition to anemia, increased platelet numbers in the $0.5 \%$ and $2 \%$ male and female groups may also be indicative of a coagulation disorder, though, unlike the carcinogenicity study, no hemorrhagic diathesis was observed in the chronic toxicity study. The NOAEL for the chronic toxicity was $0.125 \%$ for both sexes $(200.4 \mathrm{mg} / \mathrm{kg} \mathrm{b} . \mathrm{w} . /$ day for males; $241.9 \mathrm{mg} / \mathrm{kg} \mathrm{b} . \mathrm{w} . /$ day for females) as evidenced by decreased hemoglobin level and increased relative liver weight in the male and female $0.5 \%$ groups, and increased gamma-GTP activity and T-Cho concentration in the female $0.5 \%$ group.

In the carcinogenicity study, hemorrhagic diathesis was concluded to be the major cause for the decreased survival rate in the male $2 \%$ group. Although PT and APTT in the male $2 \%$ group could not be examined in the present study, prolonged PT and APTT in the male $0.5 \%$ group indicated that hemorrhagic diathesis was caused by defects in the both extrinsic and intrinsic coagulation pathways. Vitamin $\mathrm{K}$ deficiency is a well-known cause of abnormalities in these pathway as vitamin $\mathrm{K}$ is required for the synthesis of the vitamin K-dependent procoagulatants (factors II, VII, IX and X) and anticoagulants (protein C and protein S) (Mammen. 2002; Stafford 2005). In another long-term toxicity study investigating the mechanism of dammar resin-induced hemorrhagic diathesis in male F344 rats, 52-week dietary administration of dammar resin caused a significant decrease in serum vitamin $\mathrm{K}$-dependent protein $\mathrm{S}$, which is indicative of vitamin $\mathrm{K}$ status (data not shown). This result strongly suggests that a high dose of dammar resin can result in vitamin $\mathrm{K}$ deficiency and thereby elicit hemorrhagic diathesis. It is currently unclear 
as to the exact reason for the likely vitamin $\mathrm{K}$ deficiency observed in this study; possibilities include interference with the absorption of vitamin $\mathrm{K}$ from the intestine and interference with the reduction of vitamin K epoxide (Bloom and Brandt 2007).

In conclusion, the findings of the present study demonstrate that dammar resin is a hepatocarcinogen in male F344 rats and underlines the roles of inhibition of apoptosis, CYP enzyme induction, and oxidative stress in the hepatocarcinogenicity of dammar resin. Moreover, long-term dietary supplementation of dammar resin induced anemia and hemorrhagic diathesis, likely via inhibition of both extrinsic and intrinsic coagulation pathways in male and female rats. 


\section{Acknowledgements}

This work was supported by Health and Labour Sciences Research Grants from the Ministry of Health, Labor and Welfare of Japan, and a grant from The Japan Food Chemical Research Foundation. We are grateful to Dr. Robert R. Maronpot (Maronpot Consulting LLC, Raleigh, NC, USA) for reviewing this manuscript. The authors gratefully acknowledge the technical assistance of Masahiko Kushida (Sumika Partners, Osaka, Japan), Kaori Nakakubo, Rie Onodera, Keiko Sakata, Yuko Hisabayashi, and Yukiko Iura (Department of Molecular Patholoby, Osaka City University Graduate School of Medicine School, Osaka, Japan), and Shiota Masayuki and Yukimi Kira (Research Support Platform, Osaka City University Graduate School of Medicine, Osaka, Japan).

\section{Ethical standards}

The manuscript does not contain clinical studies or patient data.

\section{Conflict of interest}

The authors declare that they have no conflict of interest. 


\section{References}

Andrikopoulos NK, Kaliora AC, Assimopoulou AN, Papapeorgiou VP (2003) Biological activity of some naturally occurring resins, gums and pigments against in vitro LDL oxidation. Phytother Res 17(5):501-7 doi:10.1002/ptr.1185

Bloom JC, Brandt JT (2007) Toxic responses of the blood. In: Klaassen C (ed) Casarett \& Doull's Toxicology: The Basic Science of Poisons. Seventh Edition edn. McGraw-Hill Education

Cohen SM (2010) Evaluation of possible carcinogenic risk to humans based on liver tumors in rodent assays: the two-year bioassay is no longer necessary. Toxicol Pathol 38(3):487-501 doi:10.1177/0192623310363813

Cohen SM, Fukushima S, F.P. G, et al. (2017) 2017 GRAS flavoring substances 28. https://www.femaflavor.org/publications/gras-publications/gras-28

Dizdaroglu M, Jaruga P, Birincioglu M, Rodriguez H (2002) Free radical-induced damage to DNA: mechanisms and measurement. Free Radic Biol Med 32(11):1102-15

FSCJ (2010) Guideline for Assessment of the Effect of Food on Human Health Regarding Food Additives, Food Safety Commission of Japan (FSCJ) http://www.fsc.go.jp/english/standardsforriskassessment/guideline_assessment_f oodadditives_e2.pdf

Fukushima S, Wanibuchi H, Morimura K, et al. (2002) Lack of a dose-response relationship for carcinogenicity in the rat liver with low doses of 2-amino-3,8- 
dimethylimidazo[4,5-f]quinoxaline or N-nitrosodiethylamine. Jpn J Cancer Res 93(10):1076-82

Gibson GG, Plant NJ, Swales KE, Ayrton A, El-Sankary W (2002) Receptor-dependent transcriptional activation of cytochrome P4503A genes: induction mechanisms, species differences and interindividual variation in man. Xenobiotica 32(3):165206 doi:10.1080/00498250110102674

Hall AP, Elcombe CR, Foster JR, et al. (2012) Liver hypertrophy: a review of adaptive (adverse and non-adverse) changes--conclusions from the 3rd International ESTP Expert Workshop. Toxicol Pathol 40(7):971-94 doi:10.1177/0192623312448935

Hayashi M, Matsui M, Ishii K, Kawasaki M (2000) http://ci.nii.ac.jp/naid/110001710452/en (In japanese). Environmental Mutagen $\operatorname{Research}(22): 27-44$

INHAND, International Harmonization of Nomenclature and Diagnostic Criteria for Lesions in Rats and Mice. Society of Toxicologic Pathology. https://www.goreni.org/gr3_nom_inhand_publ.php.

JECFA (1986) Evaluation of Certain Food-Additives and Contaminants (Twenty-ninth Report of the Joint FAO/WHO Expert Committee on Food Additives). WHO Technical Report Series Evaluation of Certain Food Additives and Contaminants. vol 733, p 16

Kanki M, Gi M, Fujioka M, Wanibuchi H (2016) Detection of non-genotoxic hepatocarcinogens and prediction of their mechanism of action in rats using gene 
marker sets. J Toxicol Sci 41(2):281-92 doi:10.2131/jts.41.281

Luch A (2005) Nature and nurture - lessons from chemical carcinogenesis. Nat Rev Cancer 5(2):113-25 doi:10.1038/nrc1546

Mammen. E (2002) Thrombohemorrhagic defects in liver and renal diseases. In: Bick RL (ed) Disorders of Thrombosis and Hemostasis: Clinical and Laboratory Practice. 3rd Edition edition edn. Lippincott Williams \& Wilkins

Moon H, Ahn H, Kodell RL (2006) A Computational Tool for Testing Dose-Related Trend Using an Age-Adjusted Bootstrap-Based Poly- k Test. Journal of statistical software 16(7):1-14 doi:DOI: 10.18637/jss.v016.i07

Nebert DW, Dalton TP (2006) The role of cytochrome P450 enzymes in endogenous signalling pathways and environmental carcinogenesis. Nat Rev Cancer 6(12):947-60 doi:10.1038/nrc2015

NTP (2011) NTP historical controls report: All routes and vehicles: F344/N rats. http://ntp.niehs.nih.gov/ntp/historical_controls/ntp2000_2010/2010-03-22-histratsallroutes.pdf. Washington, DC

Poehland BL, Carte BK, Francis TA, Hyland LJ, Allaudeen HS, Troupe N (1987) In vitro antiviral activity of dammar resin triterpenoids. J Nat Prod 50(4):706-13

Rodriguez-Antona C, Ingelman-Sundberg M (2006) Cytochrome P450 pharmacogenetics and cancer. Oncogene 25(11):1679-91 doi:10.1038/sj.onc. 1209377

Schieber M, Chandel NS (2014) ROS function in redox signaling and oxidative stress. 
Curr Biol 24(10):R453-62 doi:10.1016/j.cub.2014.03.034

Stafford DW (2005) The vitamin K cycle. J Thromb Haemost 3(8):1873-8 doi:10.1111/j.1538-7836.2005.01419.x

Tompkins LM, Wallace AD (2007) Mechanisms of cytochrome P450 induction. J Biochem Mol Toxicol 21(4):176-81

Uehara T, Minowa Y, Morikawa Y, et al. (2011) Prediction model of potential hepatocarcinogenicity of rat hepatocarcinogens using a large-scale toxicogenomics database. Toxicol Appl Pharmacol 255(3):297-306 doi:10.1016/j.taap.2011.07.001

Ukiya M, Kikuchi T, Tokuda H, et al. (2010) Antitumor-promoting effects and cytotoxic activities of dammar resin triterpenoids and their derivatives. Chem Biodivers 7(8):1871-84 doi:10.1002/cbdv.201000107

USP (2012) Food chemicals codex, 8th edn. The United States Pharmacopeial Convention, Washington, DC

Xie XL, Wei M, Kakehashi A, et al. (2012) Dammar resin, a non-mutagen, induces [corrected] oxidative stress and metabolic enzymes in the liver of gpt delta transgenic mouse which is different from a mutagen, 2-amino-3methylimidazo[4,5-f]quinoline. Mutat $\quad$ Res 748(1-2):29-35 doi:10.1016/j.mrgentox.2012.06.005

Yamada F, Sumida K, Uehara T, et al. (2013) Toxicogenomics discrimination of potential hepatocarcinogenicity of non-genotoxic compounds in rat liver. J Appl Toxicol 
33(11):1284-93 doi:10.1002/jat.2790

Zangar RC, Davydov DR, Verma S (2004) Mechanisms that regulate production of reactive oxygen species by cytochrome P450. Toxicol Appl Pharmacol 199(3):316-31 doi:10.1016/j.taap.2004.01.018 


\section{Figure legends}

\section{Fig. 1}

Body weight curves. A, The chronic toxicity study; B, The carcinogenicity study.

\section{Fig. 2}

Liver lesions in male rats treated with $2 \%$ dammar resin in the chronic toxicity and carcinogenicity studies. A, Basophilic focus in a male rat in the $2 \%$ group in the chronic toxicity study. B, Mixed focus consisting of a combination of eosinophilic and clear cell hepatocytes in another male rat in the $2 \%$ group in the chronic toxicity study. C, Hepatocellular carcinoma in a male rat in the $2 \%$ group in the carcinogenicity study. D, Higher magnification of C.

\section{Fig. 3}

Survival curves in the carcinogenicity study.

\section{Fig. 4}

Effects of 2\% dammar resin in the livers of male rats in the 4-week subacute toxicity study. A, Relative mRNA expression levels of PCNA ( $n=6$ for each group). $B$, Relative mRNA expression levels of genes involved in apoptosis ( $\mathrm{n}=6$ for each group); $\mathrm{C}$, Relative mRNA expression levels of CYPs belonging to families $1-4$ ( $\mathrm{n}=6$ for each group); $\mathrm{D}$, Protein oxidation ( $\mathrm{n}=6$ for each group) and formation of $8-\mathrm{OHdG}$ in liver DNA ( $\mathrm{n}=10$ for each group). Significantly different from the control group at $* \mathrm{p}<0.05 ;{ }^{*} \mathrm{p}<0.01$; $* * * \mathrm{p}<0.01$ 


\section{Supplementary Fig.1}

Massive hemorrhages in the urinary bladder (A) and prostate (B) of a moribund male rat in the carcinogenicity study. 
Table 1 Survival, final body weights, liver weights, water and food consumption, and dammar resin intake

\begin{tabular}{|c|c|c|c|c|c|c|c|c|c|c|}
\hline \multirow{2}{*}{$\begin{array}{l}\text { Subacute toxicity study (4 weeks) } \\
\text { Dammar resin }\end{array}$} & \multicolumn{3}{|c|}{ Male } & & & \multicolumn{3}{|c|}{ Female } & & \\
\hline & 0 & $2 \%$ & $5 \%$ & & & 0 & $2 \%$ & $5 \%$ & & \\
\hline Initial no. of rats & 10 & 10 & 10 & & & 10 & 10 & 10 & & \\
\hline No. of surviving rats (\%) & $10(100 \%)$ & $10(100 \%)$ & $10(100 \%)$ & & & $10(100 \%)$ & $10(100 \%)$ & $10(100 \%)$ & & \\
\hline Final body weight $(\mathrm{g})$ & $235 \pm 7$ & $218 \pm 7 * * *$ & $199 \pm 9 * * *$ & & & $148 \pm 3$ & $144 \pm 3$ & $140 \pm 7 * *$ & & \\
\hline Absolute liver weight (g) & $9.7 \pm 0.5$ & $10 \pm 0.5$ & $10.6 \pm 0.6^{* *}$ & & & $5.1 \pm 0.1$ & $7.1 \pm 0.4^{* *}$ & $7.6 \pm 0.5 * * *$ & & \\
\hline Relative liver weight (\%) & $4.1 \pm 0.2$ & $4.6 \pm 0.2 * * *$ & $5.3 \pm 0.2 * * *$ & & & $3.5 \pm 0.04$ & $4.9 \pm 0.2 *$ & $5.4 \pm 0.3 * * *$ & & \\
\hline Average food consumption ( $\mathrm{g} /$ day/rat $)$ & 13.4 & 13.2 & 17.7 & & & 9.8 & 10.2 & 15.3 & & \\
\hline Average water consumption ( $\mathrm{g} / \mathrm{day} / \mathrm{rat}$ ) & 18.3 & 18.8 & 18.2 & & & 14.4 & 15.0 & 14.5 & & \\
\hline Chronic toxicity study (52 weeks) & \multicolumn{5}{|c|}{ Male } & \multicolumn{5}{|c|}{ Female } \\
\hline Dammar resin & 0 & $0.03 \%$ & $0.125 \%$ & $0.5 \%$ & $2 \%$ & 0 & $0.03 \%$ & $0.125 \%$ & $0.5 \%$ & $2 \%$ \\
\hline Initial no. of rats & 10 & 10 & 10 & 10 & 10 & 10 & 10 & 10 & 10 & 10 \\
\hline No. of surviving rats (\%) & $10(100 \%)$ & $10(100 \%)$ & $10(100 \%)$ & $10(100 \%)$ & $10(100 \%)$ & $10(100 \%)$ & $10(100 \%)$ & $10(100 \%)$ & $10(100 \%)$ & $10(100 \%)$ \\
\hline Final body weight $(\mathrm{g})$ & $449 \pm 22$ & $477 \pm 19 *$ & $461 \pm 25$ & $461 \pm 29$ & $402 \pm 2 * * *$ & $224 \pm 10$ & $240 \pm 7 * *$ & $238 \pm 15$ & $233 \pm 19$ & $208 \pm 10$ \\
\hline Absolute liver weight (g) & $9.3 \pm 0.5$ & $9.9 \pm 0.6$ & $9.8 \pm 0.6$ & $10.4 \pm 1^{* *}$ & $10.7 \pm 0.8^{* * *}$ & $4.7 \pm 0.4$ & $5 \pm 0.3$ & $5 \pm 0.5$ & $6.1 \pm 0.8^{* *}$ & $6.7 \pm 0.5^{* * *}$ \\
\hline Relative liver weight (\%) & $2.1 \pm 0.2$ & $2.1 \pm 0.1$ & $2.1 \pm 0.1$ & $2.3 \pm 0.1$ & $2.7 \pm 0.1 * * *$ & $2.1 \pm 0.2$ & $2.1 \pm 0.1$ & $2.1 \pm 0.2$ & $2.6 \pm 0.2 * * *$ & $3.3 \pm 0.2 * * *$ \\
\hline Average food consumption ( $\mathrm{g} / \mathrm{day} / \mathrm{rat})$ & 13.6 & 14.4 & 14.1 & 14.1 & 13.5 & 9 & 9.4 & 9.5 & 9.4 & 9.1 \\
\hline Average water consumption ( $\mathrm{g} / \mathrm{day} / \mathrm{rat})$ & 18.9 & 19.8 & 19.3 & 20.7 & 21.8 & 14.9 & 14.9 & 14.3 & 14.7 & 15.6 \\
\hline Average dammar resin intake $(\mathrm{mg} / \mathrm{kg}$ b.w./day $)$ & 0 & 11.9 & 49.6 & 200.4 & 856.7 & 0 & 14.3 & 59.2 & 241.9 & 997.9 \\
\hline Carcinogenicity study (104 weeks) & \multicolumn{3}{|c|}{ Male } & & & \multicolumn{4}{|c|}{ Female } & \\
\hline Dammar resin & 0 & $0.03 \%$ & $0.5 \%$ & $2 \%$ & & 0 & $0.03 \%$ & $0.5 \%$ & $2 \%$ & \\
\hline Initial No. of rats & 50 & 50 & 50 & 50 & & 50 & 50 & 50 & 50 & \\
\hline No. of surviving rats (\%) & $43(86 \%)$ & $41(82 \%)$ & $40(80 \%)$ & $22(44 \%)$ & & $37(74 \%)$ & $43(86 \%)$ & $46(92 \%)$ & $42(84 \%)$ & \\
\hline Final body weight $(\mathrm{g})$ & $471 \pm 34$ & $481 \pm 44$ & $456 \pm 27$ & $417 \pm 29^{*}$ & & $283 \pm 26$ & $316 \pm 31 * *$ & $292 \pm 29$ & $261 \pm 22^{*}$ & \\
\hline Absolute liver weight $(g)^{a}$ & $11 \pm 1.1$ & $12.1 \pm 1^{* *}$ & $13.4 \pm 1.6^{* * *}$ & $14.7 \pm 3.1 * * *$ & & $6.2 \pm 1$ & $6.7 \pm 1 *$ & $7.8 \pm 1.5^{* * *}$ & $8.8 \pm 1.4^{* * *}$ & \\
\hline Relative liver weight (\%) ${ }^{\mathrm{a}}$ & $2.3 \pm 0.2$ & $2.5 \pm 0.3^{*}$ & $2.9 \pm 0.3 * * *$ & $3.6 \pm 1 . * * *$ & & $2.2 \pm 0.3$ & $2.1 \pm 0.2$ & $2.7 \pm 0.4^{* * *}$ & $3.4 \pm 0.4^{* * *}$ & \\
\hline Average food consumption (g/day/rat) & 13.7 & 14.5 & 14.5 & 14.2 & & 9 & 9.5 & 9.3 & 9.1 & \\
\hline Average water consumption ( $\mathrm{g} / \mathrm{day} / \mathrm{rat}$ ) & 18.1 & 19.1 & 19.6 & 20.2 & & 14.9 & 14.7 & 14.5 & 15.1 & \\
\hline Average dammar resin intake $(\mathrm{mg} / \mathrm{kg}$ b.w. $/$ day $)$ & 0 & 10.5 & 178.3 & 766.9 & & 0 & 12.2 & 205.4 & 868.1 & \\
\hline
\end{tabular}

${ }^{a}$ Liver weights of rats surviving to the end of the experiment.

Significantly different from the respective control at $* \mathrm{p}<0.05 ; * * \mathrm{p}<0.01 ; * * * \mathrm{p}<0.001$, respectively. 
Table 2 Hematology and serum biochemistry analyses, and urinalysis in the 52-week chronic toxicity study

\begin{tabular}{|c|c|c|c|c|c|c|c|c|c|c|}
\hline \multirow{3}{*}{$\begin{array}{c}\text { Dammar resin } \\
\text { No. of rats examined }\end{array}$} & \multicolumn{5}{|c|}{ Male } & \multicolumn{5}{|c|}{ Female } \\
\hline & 0 & $0.03 \%$ & $0.125 \%$ & $0.5 \%$ & $2 \%$ & 0 & $0.03 \%$ & $0.125 \%$ & $0.5 \%$ & $2 \%$ \\
\hline & 10 & 10 & 10 & 10 & 10 & 10 & 10 & 10 & 10 & 10 \\
\hline \multicolumn{11}{|l|}{ Hematology } \\
\hline $\mathrm{WBC}(/ \mu \mathrm{l})$ & $3190 \pm 606$ & $2790 \pm 559$ & $2610 \pm 415^{*}$ & $2250 \pm 350 * * *$ & $2630 \pm 432 *$ & $2360 \pm 832$ & $2150 \pm 327$ & $1930 \pm 386$ & $2400 \pm 476$ & $2470 \pm 371$ \\
\hline $\operatorname{RBC}\left(10^{4} / 1\right)$ & $902 \pm 14$ & $921 \pm 15^{*}$ & $912 \pm 12$ & $888 \pm 15$ & $869 \pm 24 * * *$ & $867 \pm 39$ & $863 \pm 40$ & $856 \pm 16$ & $865 \pm 45$ & $833 \pm 43$ \\
\hline $\mathrm{Hb}(\mathrm{g} / \mathrm{dl})$ & $15.0 \pm 0.4$ & $14.9 \pm 0.2$ & $14.8 \pm 0.2$ & $14.5 \pm 0.4 * *$ & $14.1 \pm 0.5 * * *$ & $15.7 \pm 0.7$ & $15.6 \pm 0.8$ & $15.3 \pm 0.4$ & $15.3 \pm 1.3^{*}$ & $14.3 \pm 0.8 * *$ \\
\hline $\operatorname{Plt}\left(10^{4} / \mu 1\right)$ & $60.3 \pm 3.8$ & $63.1 \pm 2.6$ & $59.9 \pm 3.0$ & $67.9 \pm 3.2 * * *$ & $71.6 \pm 3.5 * * *$ & $48.0 \pm 8.4$ & $51.1 \pm 3.0$ & $52.1 \pm 3.5$ & $58.6 \pm 5.3^{*}$ & $69.7 \pm 17.7 * *$ \\
\hline $\mathrm{Ht}(\%)$ & $45.3 \pm 0.6$ & $45.8 \pm 1.2$ & $45.6 \pm 0.6$ & $44.8 \pm 0.9$ & $44.7 \pm 1.4$ & $48.2 \pm 2.7$ & $48.9 \pm 2.7$ & $48.7 \pm 1.5$ & $49.6 \pm 2.6$ & $49.0 \pm 2.5$ \\
\hline $\operatorname{MCV}(\mathrm{fl})$ & $50.2 \pm 0.7$ & $49.7 \pm 1.3$ & $50.0 \pm 0.6$ & $50.4 \pm 0.6$ & $51.4 \pm 0.8^{*}$ & $55.6 \pm 1.4$ & $56.6 \pm 1.2$ & $56.8 \pm 1.3$ & $57.4 \pm 1.5^{*}$ & $58.9 \pm 1.7 * * *$ \\
\hline $\mathrm{MCH}(\mathrm{pg})$ & $16.6 \pm 0.4$ & $16.2 \pm 0.2 * * *$ & $16.2 \pm 0.2 * * *$ & $16.3 \pm 0.3^{*}$ & $16.2 \pm 0.2 * * *$ & $18.1 \pm 0.2$ & $18.1 \pm 0.2$ & $17.9 \pm 0.2 *$ & $17.6 \pm 0.6 * *$ & $17.2 \pm 0.3^{* * *}$ \\
\hline MCHC (\%) & $33.1 \pm 0.6$ & $32.5 \pm 0.6^{*}$ & $32.4 \pm 0.3 *$ & $32.4 \pm 0.5^{* *}$ & $31.5 \pm 0.5^{* * *}$ & $32.6 \pm 0.9$ & $32.0 \pm 0.6$ & $31.4 \pm 0.7^{*}$ & $30.8 \pm 1.5^{*}$ & $29.2 \pm 0.7^{* * *}$ \\
\hline \multicolumn{11}{|l|}{ Biochemistry } \\
\hline AST (IU/1) & $117 \pm 41$ & $177 \pm 50$ & $149 \pm 21$ & $118 \pm 28^{* *}$ & $66 \pm 7 * *$ & $125 \pm 36$ & $103 \pm 19$ & $108 \pm 23$ & $87 \pm 16^{* *}$ & $69 \pm 15^{* *}$ \\
\hline $\mathrm{ALT}(\mathrm{IU} / 1)$ & $107 \pm 26$ & $110 \pm 23$ & $90 \pm 11.44$ & $63 \pm 13^{* *}$ & $49 \pm 5 * *$ & $53 \pm 12$ & $48 \pm 10$ & $46 \pm 5$ & $41 \pm 5 * *$ & $43 \pm 5^{*}$ \\
\hline $\operatorname{ALP}(\mathrm{IU} / 1)$ & $376 \pm 30$ & $370 \pm 50$ & $333 \pm 47$ & $291 \pm 39^{* *}$ & $284 \pm 14 * *$ & $234 \pm 56$ & $205 \pm 46$ & $189 \pm 32$ & $148 \pm 26^{* *}$ & $184 \pm 38$ \\
\hline gammar-GTP (IU/1) & $3.1 \pm 1.9$ & $3.0 \pm 1.1$ & $3.7 \pm 2.2$ & $2.5 \pm 1.3$ & $2.2 \pm 0.6$ & $1.1 \pm 0.3$ & $1.2 \pm 0.6$ & $1.4 \pm 0.5$ & $2.5 \pm 0.5^{* *}$ & $15.6 \pm 4.0^{* * *}$ \\
\hline $\mathrm{TP}(\mathrm{g} / \mathrm{dl})$ & $6.8 \pm 0.2$ & $6.7 \pm 0.2$ & $6.6 \pm 0.2$ & $6.8 \pm 0.2$ & $6.9 \pm 0.2$ & $6.9 \pm 0.6$ & $7.2 \pm 0.3$ & $7.4 \pm 0.4 *$ & $7.7 \pm 0.3 * * *$ & $7.4 \pm 0.3 *$ \\
\hline $\operatorname{ALB}(\mathrm{g} / \mathrm{dl})$ & $4.5 \pm 0.1$ & $4.5 \pm 0.1$ & $4.5 \pm 0.1$ & $4.5 \pm 0.1$ & $4.7 \pm 0.2$ & $5.2 \pm 0.5$ & $5.4 \pm 0.2$ & $5.5 \pm 0.3$ & $5.7 \pm 0.2 *$ & $5.3 \pm 0.2$ \\
\hline A/Gratio & $2.0 \pm 0.1$ & $2.0 \pm 0.1$ & $2.0 \pm 0.1$ & $2.0 \pm 0.1$ & $2.2 \pm 0.2$ & $3.2 \pm 0.4$ & $3.1 \pm 0.34$ & $3.0 \pm 0.1$ & $2.9 \pm 0.2$ & $2.6 \pm 0.1 *$ \\
\hline $\mathrm{TG}(\mathrm{mg} / \mathrm{dl})$ & $92.1 \pm 17.6$ & $91.2 \pm 29.1$ & $69.6 \pm 17.9$ & $51.6 \pm 19.8 * * *$ & $61.5 \pm 14.8 * * *$ & $84.5 \pm 33.2$ & $119.5 \pm 45.3$ & $131 \pm 54.3$ & $138.9 \pm 34.5^{*}$ & $97.2 \pm 49.6$ \\
\hline T-Cho (mg/dl) & $81.7 \pm 7.2$ & $86.3 \pm 7.5$ & $84.1 \pm 9.1$ & $83.1 \pm 8.1$ & $94 \pm 9.6^{* *}$ & $106.8 \pm 16.9$ & $110.9 \pm 12.4$ & $119.3 \pm 19.1$ & $139.5 \pm 16.5 * * *$ & $162 \pm 22 * * *$ \\
\hline Creatinine (mg/dl ) & $0.31 \pm 0.04$ & $0.32 \pm 0.05$ & $0.30 \pm 0.05$ & $0.27 \pm 0.03$ & $0.28 \pm 0.05$ & $0.28 \pm 0.05$ & $0.30 \pm 0.04$ & $0.29 \pm 0.04$ & $0.28 \pm 0.03$ & $0.26 \pm 0.03$ \\
\hline BUN (mg/dl ) & $20.3 \pm 4.5$ & $19.9 \pm 3.1$ & $19.4 \pm 2.8$ & $17.5 \pm 2.5$ & $22.3 \pm 4.7$ & $26.3 \pm 4.4$ & $20.8 \pm 4.1^{*}$ & $22.3 \pm 3.5$ & $23.7 \pm 4.4$ & $26.3 \pm 5.8$ \\
\hline $\mathrm{Na}(\mathrm{mEq} / 1)$ & $144.7 \pm 1.3$ & $144.5 \pm 1.6$ & $144 \pm 1.8$ & $144.7 \pm 1.2$ & $145.2 \pm 0.8$ & $144.2 \pm 1.7$ & $144.6 \pm 2.0$ & $144.3 \pm 1.6$ & $144.9 \pm 1.3$ & $143.8 \pm 1.5$ \\
\hline $\mathrm{K}(\mathrm{mEq} / 1)$ & $4.5 \pm 0.3$ & $4.6 \pm 0.2$ & $4.6 \pm 0.4$ & $4.6 \pm 0.4$ & $4.3 \pm 0.4$ & $4.5 \pm 0.3$ & $4.4 \pm 0.5$ & $4.3 \pm 0.2$ & $4.2 \pm 0.4$ & $4.5 \pm 0.4$ \\
\hline $\mathrm{Cl}(\mathrm{mEq} / 1)$ & $103.5 \pm 1.3$ & $103.5 \pm 2.0$ & $102.4 \pm 1.8$ & $101.3 \pm 1.8^{*}$ & $102.1 \pm 1.1$ & $100.9 \pm 1.3$ & $101.6 \pm 1.1$ & $101.6 \pm 1.5$ & $100.3 \pm 1.4$ & $100.6 \pm 1.1$ \\
\hline $\mathrm{Ca}(\mathrm{mg} / \mathrm{d} 1)$ & $10.3 \pm 0.2$ & $10.4 \pm 0.3$ & $10.2 \pm 0.1$ & $10.4 \pm 0.3$ & $10.7 \pm 0.1 * *$ & $10.3 \pm 0.5$ & $10.5 \pm 0.4$ & $10.5 \pm 0.5$ & $10.9 \pm 0.3$ & $10.4 \pm 0.4$ \\
\hline $\mathrm{P}(\mathrm{mg} / \mathrm{dl})$ & $5.1 \pm 0.8$ & $5.4 \pm 0.6$ & $5.3 \pm 0.6$ & $5.5 \pm 0.4$ & $5.3 \pm 0.5$ & $4.4 \pm 0.8$ & $4.0 \pm 1.3$ & $4.1 \pm 0.7$ & $4.6 \pm 0.9$ & $5.2 \pm 0.8$ \\
\hline \multicolumn{11}{|l|}{ Urinalysis } \\
\hline \multicolumn{11}{|l|}{ Protein } \\
\hline 0 & 0 & 0 & 0 & 0 & 0 & 0 & 0 & 0 & 0 & 0 \\
\hline $30 \mathrm{mg} / \mathrm{dl}$ & 0 & 0 & 0 & 0 & 0 & 2 & 5 & 4 & 0 & 3 \\
\hline $100 \mathrm{mg} / \mathrm{dl}$ & 6 & 6 & 4 & 1 & 0 & 7 & 5 & 4 & 5 & 5 \\
\hline $\begin{array}{l}\geqq 300 \mathrm{mg} / \mathrm{dl} \\
\mathrm{WBC}\end{array}$ & 4 & 4 & 6 & 9 & $10^{*}$ & 1 & 0 & 2 & 5 & 2 \\
\hline- & 1 & 1 & 0 & 0 & 0 & 10 & 8 & 7 & 1 & 1 \\
\hline$+/-$ & 7 & 8 & 8 & 5 & 1 & 0 & 2 & 3 & 9 & 8 \\
\hline $1+$ & 2 & 1 & 2 & 3 & 2 & 0 & 0 & 0 & 0 & 1 \\
\hline $3+$ & 0 & 0 & 0 & 2 & $7 * *$ & 0 & 0 & 0 & 0 & 0 \\
\hline
\end{tabular}

Significantly different from the respective control at $* \mathrm{p}<0.05 ;{ }^{* *} \mathrm{p}<0.01 ; * * * \mathrm{p}<0.001$, respectively. 
Table 3 Histopathological findings in livers and kidneys in the 52-week chronic toxicity study

\begin{tabular}{|c|c|c|c|c|c|c|c|c|c|c|c|c|}
\hline & \multirow[b]{2}{*}{ Dammar resin } & & \multicolumn{5}{|c|}{ Male } & \multicolumn{5}{|c|}{ Female } \\
\hline & & & 0 & $0.03 \%$ & $0.125 \%$ & $0.5 \%$ & $2 \%$ & 0 & $0.03 \%$ & $0.125 \%$ & $0.5 \%$ & $2 \%$ \\
\hline & No. of rats examined & & 10 & 10 & 10 & 10 & 10 & 10 & 10 & 10 & 10 & 10 \\
\hline \multicolumn{13}{|l|}{ Liver } \\
\hline \multicolumn{13}{|c|}{$\begin{array}{l}\text { Foci of } \\
\text { cellular alteration }\end{array}$} \\
\hline & Incidence (\%) & & 0 & 0 & 0 & 0 & $2(2)$ & 0 & 0 & 0 & 0 & 0 \\
\hline & Mulitplicity (no./rat) & & 0 & 0 & 0 & 0 & $0.3 \pm 0.7$ & 0 & 0 & 0 & 0 & 0 \\
\hline & \multirow[t]{4}{*}{ Bile duct hyperplasia ${ }^{a}$} & $1+$ & 0 & 0 & 0 & 0 & 0 & 7 & 7 & 6 & 8 & 10 \\
\hline & & $2+$ & 0 & 0 & 0 & 0 & 8 & 3 & 3 & 3 & 2 & 0 \\
\hline & & $3+$ & 7 & 7 & 7 & 8 & $2^{*}$ & 0 & 0 & 1 & 0 & 0 \\
\hline & & $4+$ & 3 & 3 & 3 & 2 & 0 & 0 & 0 & 0 & 0 & 0 \\
\hline \multicolumn{13}{|l|}{ Kidney } \\
\hline & \multirow[t]{3}{*}{ Proteinaceous cast $^{\mathrm{a}}$} & $1+$ & 5 & 6 & 2 & 1 & 0 & 3 & 4 & 1 & 2 & 1 \\
\hline & & $2+$ & 5 & 3 & 6 & 6 & 2 & 7 & 5 & 6 & 6 & 8 \\
\hline & & $3+$ & 0 & 1 & 2 & 3 & $8^{* *}$ & 0 & 1 & 2 & 3 & 0 \\
\hline
\end{tabular}

${ }^{\mathrm{a}} 1+$ : minimal; $2+$ : slight; $3+$ : moderate; $4+$ : extensive.

Significantly different from the respective control at $* \mathrm{p}<0.05$; $* * \mathrm{p}<0.001$, respectively. 
Table 4 Hematology and coagulation factor analyses in the 104-week chronic toxicity/carcinogenicity study

\begin{tabular}{|c|c|c|c|c|c|c|c|c|}
\hline \multirow[b]{2}{*}{ Dammar resin } & \multicolumn{3}{|c|}{ Male } & \multicolumn{5}{|c|}{ Female } \\
\hline & 0 & $0.03 \%$ & $0.5 \%$ & $2 \%$ & 0 & $0.03 \%$ & $0.5 \%$ & $2 \%$ \\
\hline \multicolumn{9}{|l|}{ Hematology } \\
\hline No. of rats examined & 17 & 10 & 9 & 17 & 10 & 10 & 10 & 10 \\
\hline $\mathrm{WBC}(/ \mu \mathrm{l})$ & $3400 \pm 1320$ & $3580 \pm 605$ & $2744 \pm 600$ & $2956 \pm 715$ & $2790 \pm 1343$ & $2150 \pm 725$ & $2600 \pm 1265$ & $2240 \pm 458$ \\
\hline $\operatorname{RBC}\left(10^{4} / 1\right)$ & $873 \pm 135$ & $851 \pm 40$ & $867 \pm 41$ & $747 \pm 107 * * *$ & $794 \pm 54$ & $790 \pm 32$ & $784 \pm 33$ & $785 \pm 44$ \\
\hline $\mathrm{Hb}(\mathrm{g} / \mathrm{dl})$ & $14.6 \pm 2.4$ & $14.3 \pm 0.5$ & $14.4 \pm 0.7$ & $11.9 \pm 0.9 * * *$ & $14.4 \pm 1.3$ & $14.2 \pm 0.5$ & $14 \pm 1.5$ & $13.6 \pm 1$ \\
\hline Plt $\left(10^{4} / \mu 1\right)$ & $68.5 \pm 8.1$ & $61.5 \pm 4$ & $70.7 \pm 4.9$ & $76.2 \pm 11.4^{*}$ & $52.2 \pm 9$ & $50.6 \pm 8$ & $58.3 \pm 12.5$ & $69.4 \pm 5.4 * * *$ \\
\hline $\mathrm{Ht}(\%)$ & $48.5 \pm 7.3$ & $48.1 \pm 1.1$ & $49.1 \pm 2.7$ & $42.2 \pm 5.8^{*}$ & $44.9 \pm 3.2$ & $44.9 \pm 1.8$ & $45.1 \pm 4.1$ & $45.4 \pm 3.2$ \\
\hline $\operatorname{MCV}(\mathrm{fl})$ & $56 \pm 3$ & $57 \pm 2$ & $57 \pm 3$ & $57 \pm 2$ & $56 \pm 3$ & $57 \pm 2$ & $57 \pm 4$ & $58 \pm 2$ \\
\hline $\mathrm{MCH}(\mathrm{pg})$ & $16.8 \pm 0.7$ & $16.8 \pm 0.5$ & $16.6 \pm 0.6$ & $15.9 \pm 0.5^{* * *}$ & $18.1 \pm 1$ & $18 \pm 0.5$ & $17.8 \pm 1.4$ & $17.3 \pm 0.4^{*}$ \\
\hline $\mathrm{MCHC}(\%)$ & $30.1 \pm 1.5$ & $29.6 \pm 1$ & $29.3 \pm 0.7$ & $28.2 \pm 1 * * *$ & $32 \pm 1.1$ & $31.6 \pm 0.7$ & $30.9 \pm 0.8$ & $29.9 \pm 0.7 * * *$ \\
\hline \multicolumn{9}{|l|}{ Coagulation factors } \\
\hline No. of rats examined & 8 & 8 & 7 & & 10 & 10 & 10 & 10 \\
\hline PT (sec.) & $8.3 \pm 0.1$ & $8.3 \pm 0.2$ & $11.2 \pm 2.4 * *$ & N.E. & $9.1 \pm 0.5$ & $8.4 \pm 0.5$ & $8.2 \pm 0.2^{* *}$ & $16.0 \pm 9.6$ \\
\hline APTT (sec.) & $19.9 \pm 0$ & $19.9 \pm 0$ & $20.1 \pm 0.2 *$ & N.E. & $24.7 \pm 3$ & $23.2 \pm 2.9$ & $22 \pm 2.4$ & $29.4 \pm 7.1$ \\
\hline
\end{tabular}

Significantly different from the respective control at $* \mathrm{p}<0.05, * * \mathrm{p}<0.01, * * * \mathrm{p}<0.001$, respectively.

N.E., no examined. 
Table 5 Incidence and multiplicity of hepatocellular tumor in the 104-week carcinogenicity study

\begin{tabular}{|c|c|c|c|c|c|c|c|}
\hline \multirow{2}{*}{$\begin{array}{c}\text { Dammar } \\
\text { resin }\end{array}$} & \multirow{2}{*}{$\begin{array}{c}\text { No. of } \\
\text { rats }\end{array}$} & \multicolumn{2}{|c|}{$\begin{array}{c}\text { Hepatocellular } \\
\text { adenoma }\end{array}$} & \multicolumn{2}{|c|}{$\begin{array}{c}\text { Hepatocellular } \\
\text { carcinoma }\end{array}$} & \multicolumn{2}{|c|}{$\begin{array}{c}\text { Total } \\
\text { (adenoma and/or carcinoma) }\end{array}$} \\
\hline & & Incidence $(\%)$ & Multiplicity $^{\mathrm{a}}$ & Incidence $(\%)$ & Multiplicity $^{\mathrm{a}}$ & Incidence $(\%)$ & Multiplicity \\
\hline \multicolumn{8}{|l|}{ Male } \\
\hline 0 & 50 & 0 & 0 & $0(0)$ & 0 & $0(0)$ & 0 \\
\hline $0.03 \%$ & 50 & $1(2)$ & $0.04 \pm 0.28$ & $0(0)$ & 0 & $1(2)$ & $0.04 \pm 0.28$ \\
\hline $0.5 \%$ & 50 & 0 & 0 & $0(0)$ & 0 & $0(0)$ & 0 \\
\hline $2 \%$ & 50 & $11(22) * *$ & $0.46 \pm 0.97 * *$ & $5(10)^{*}$ & $0.12 \pm 0.39 * *$ & $15^{\mathrm{a}}(30) * *$ & $0.58 \pm 1.03 * *$ \\
\hline Poly-k test & & $\uparrow \uparrow$ & & $\uparrow \uparrow$ & & $\uparrow \uparrow$ & \\
\hline \multicolumn{8}{|l|}{ Female } \\
\hline Control & 49 & $1(2)$ & $0.02 \pm 0.14$ & $0(0)$ & 0 & $1(2)$ & $0.02 \pm 0.14$ \\
\hline $0.03 \%$ & 50 & 0 & 0 & $0(0)$ & 0 & $0(0)$ & 0 \\
\hline $0.5 \%$ & 50 & $1(2)$ & $0.02 \pm 0.14$ & $0(0)$ & 0 & $1(2)$ & $0.02 \pm 0.14$ \\
\hline $2 \%$ & 50 & $1(2)$ & $0.02 \pm 0.14$ & $1(2)$ & $0.04 \pm 0.28$ & $2(4)$ & $0.06 \pm 0.31$ \\
\hline Poly-k test & & & & $\uparrow$ & & & \\
\hline
\end{tabular}

${ }^{a}$ one rat had one adenoma and one adenocarcinoma.

Significantly different from control group $(0 \%)$ at $* \mathrm{p}<0.05$, ${ }^{*} \mathrm{p}<0.01$ by Fisher's exact test, respectively.

Significantly different at $\uparrow \mathrm{p}<0.05, \uparrow \uparrow \mathrm{p}<0.0001$ by Poly-k test, respectively. 
Table 6 Neoplastic lesions in organs/tissues other than liver in the 104-week rat carcinogenicity

\begin{tabular}{|c|c|c|c|c|c|c|c|c|c|c|}
\hline \multirow{2}{*}{$\begin{array}{l}\text { Organ } \\
\text { and }\end{array}$} & \multicolumn{4}{|c|}{ Male } & \multicolumn{6}{|c|}{ Female } \\
\hline & 1 & 2 & 3 & 4 & & 5 & 6 & 7 & 8 & \\
\hline Dammar resin $(\%)$ & 0 & 0.03 & 0.5 & 2 & Poly-k test & 0 & 0.03 & 0.5 & 2 & Poly-k test \\
\hline No. of animals examined & 50 & 50 & 50 & 50 & & $49^{\mathrm{a}}$ & 50 & 50 & 50 & \\
\hline \multicolumn{11}{|l|}{ Pituitary } \\
\hline Adenoma, pars distalis & 13 & 9 & 11 & 10 & & 23 & 18 & 17 & $12 *$ & \\
\hline Carcinoma, pars distalis & 1 & 1 & 0 & 1 & & 3 & 1 & 2 & 1 & \\
\hline Total & 14 & 10 & 11 & 11 & & 26 & 19 & 19 & $13 * *$ & \\
\hline \multicolumn{11}{|l|}{ Thyroid } \\
\hline Adenoma, C-cell & 9 & 15 & 12 & 7 & & 8 & 2 & 8 & 3 & \\
\hline Carcinoma, C-cell & 5 & 3 & 2 & 1 & & 2 & 3 & 0 & 0 & \\
\hline Adenoma, Follicular cell & 0 & 0 & 0 & 0 & & 0 & 1 & 0 & 0 & \\
\hline Total & 14 & $17^{\mathrm{b}}$ & 14 & $7^{\mathrm{b}}$ & & $9^{b}$ & 6 & 8 & 3 & \\
\hline \multicolumn{11}{|l|}{ Adrenal } \\
\hline Adenoma, cortical & 0 & 1 & 0 & 0 & & 0 & 1 & 0 & 0 & \\
\hline Ganglioneuroma & 1 & 0 & 0 & 0 & & 0 & 0 & 0 & 0 & \\
\hline Benign pheochromocytoma & 3 & 1 & 2 & 1 & & 0 & 0 & 2 & 0 & \\
\hline Malignant pheochromocytoma & 2 & 2 & 3 & 0 & & 0 & 0 & 0 & 0 & \\
\hline Total & 6 & 4 & 5 & 1 & & 0 & 1 & 2 & 0 & \\
\hline \multicolumn{11}{|l|}{ Lung/bronchial } \\
\hline Adenoma, bronchiolo-alveolar & 1 & 1 & 0 & 1 & & 0 & 0 & 0 & 1 & $\uparrow$ \\
\hline Adenocarcinoma, bronchiolo-alveolar & 0 & 1 & 0 & 0 & & 1 & 1 & 0 & 0 & \\
\hline Total & 1 & 2 & 0 & 1 & & 1 & 1 & 0 & 1 & \\
\hline Tongue & & & & & & & & & & \\
\hline Papilloma, squamous cell & 1 & 0 & 0 & 0 & & 0 & 0 & 0 & 0 & \\
\hline Jejunum & & & & & & & & & & \\
\hline Adenocarcinoma & 0 & 0 & 0 & 1 & $\uparrow$ & 0 & 0 & 0 & 0 & \\
\hline Colon & & & & & & & & & & \\
\hline Adenoma & 0 & 0 & 0 & 0 & & 0 & 0 & 0 & 1 & $\uparrow$ \\
\hline Leiomyosarcoma & 0 & 0 & 0 & 0 & & 0 & 1 & 0 & 0 & \\
\hline Pancreas & & & & & & & & & & \\
\hline Adenoma, islet cell & 7 & 6 & 3 & $1^{*}$ & & 0 & 3 & 1 & 0 & \\
\hline Carcinoma, islet cell & 1 & 0 & 1 & 2 & & 0 & 0 & 0 & 0 & \\
\hline Total & 8 & 6 & 4 & 3 & & 0 & 3 & 1 & 0 & \\
\hline Kidney & & & & & & & & & & \\
\hline Adenoma, renal cell & 0 & 1 & 1 & 0 & & 0 & 0 & 0 & 0 & \\
\hline Carcinoma, renal cell & 0 & 0 & 1 & 0 & & 1 & 0 & 0 & 0 & \\
\hline Neophroblastoma & 0 & 0 & 1 & 0 & & 0 & 0 & 0 & 0 & \\
\hline Total & 0 & 1 & 3 & 0 & & 1 & 0 & 0 & 0 & \\
\hline Preputial/ Clitoral gland & & & & & & & & & & \\
\hline Carcinoma & 3 & 3 & 4 & 0 & & 2 & 2 & 3 & 1 & \\
\hline Mammary gland & & & & & & & & & & \\
\hline Adenoma & 0 & 0 & 0 & 1 & & 2 & 1 & 2 & 1 & \\
\hline Fibroadenoma & 1 & 1 & 0 & 0 & & 5 & 6 & 5 & 9 & \\
\hline Adenocarcinoma & 0 & 0 & 0 & 0 & & 0 & 0 & 2 & 2 & \\
\hline Total & 1 & 1 & 0 & 1 & & $6^{\mathrm{c}}$ & 7 & $8^{\mathrm{d}}$ & 12 & \\
\hline Prostate & & & & & & & & & & \\
\hline Adenoma & 0 & 0 & 0 & 1 & & & & & & \\
\hline Testis & & & & & & & & & & \\
\hline Tumor, interstitial cell, benign & 35 & 41 & 34 & $24^{*}$ & & & & & & \\
\hline Ovary & & & & & & & & & & \\
\hline Granulosa cell tumor & & & & & & 2 & 1 & 0 & 0 & \\
\hline Uterus & & & & & & & & & & \\
\hline Polyp, endometrial stromal & & & & & & 13 & 9 & 10 & 6 & \\
\hline Adenoma & & & & & & 0 & 1 & 1 & 0 & \\
\hline Adenocarcinoma & & & & & & 0 & 1 & 0 & 0 & \\
\hline Sarcoma, endometrial stromal & & & & & & 3 & 3 & 2 & 3 & \\
\hline Skin/subcutis & & & & & & & & & & \\
\hline Fibroma & 6 & 5 & 3 & $0^{*}$ & & 0 & 1 & 1 & 0 & \\
\hline Keratoacanthoma & 3 & 0 & 3 & 2 & & 0 & 0 & 0 & 0 & \\
\hline Lipoma & 2 & 1 & 0 & 0 & & 0 & 1 & 0 & 0 & \\
\hline Basal cell tumor, bengin & 0 & 0 & 1 & 0 & & 0 & 0 & 0 & 0 & \\
\hline Trichoepithelioma & 0 & 0 & 0 & 0 & & 0 & 0 & 1 & 0 & \\
\hline Fibrosarcoma & 0 & 3 & 1 & 0 & & 0 & 0 & 0 & 0 & \\
\hline Hemangiosarcoma & 0 & 0 & 1 & 0 & & 0 & 0 & 0 & 0 & \\
\hline Abdominal cavity & & & & & & & & & & \\
\hline Mesothelioma & 2 & 2 & 2 & 0 & & 0 & 0 & 0 & 0 & \\
\hline Hemagiosarcoma & 0 & 0 & 0 & 0 & & 0 & 1 & 0 & 0 & \\
\hline All sites & & & & & & & & & & \\
\hline Leukemia, large granular lymphocytic & 2 & 4 & 4 & 6 & & 9 & 1 & 2 & 7 & \\
\hline Malignant lymphoma/leukemia & 0 & 0 & 0 & 0 & & 0 & 0 & 0 & 1 & \\
\hline
\end{tabular}

${ }^{a}$ one rat died at week 15 and was not included in analysis.

${ }^{\mathrm{b}}$ one rat had one $\mathrm{C}$-cell adenoma and one C-cell adenocarcinoma.

${ }^{c}$ one rat had one adenoma and one fibroadenoma

$\mathrm{d}$ one rat had one fibroadenoma and one adenocarcinoma

Significantly different from control group $(0 \%)$ at $* \mathrm{p}<0.05,{ }^{*} \mathrm{p}<0.01$ by Fisher's exact test, respectively.

Significantly different at $\uparrow \mathrm{p}<0.05$. 
Fig. 1

A The 52-week chronic toxicity study

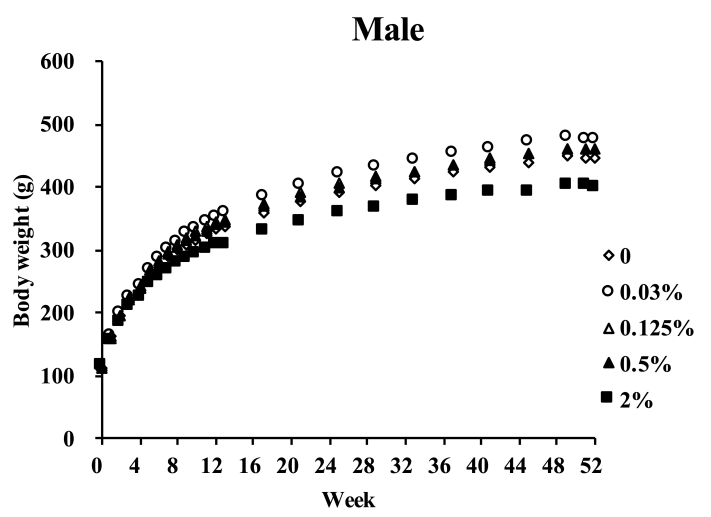

Female

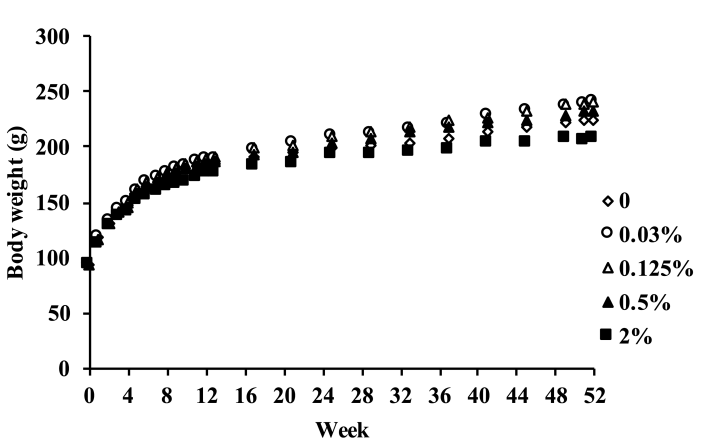

B The 104-week carcinogenicity study
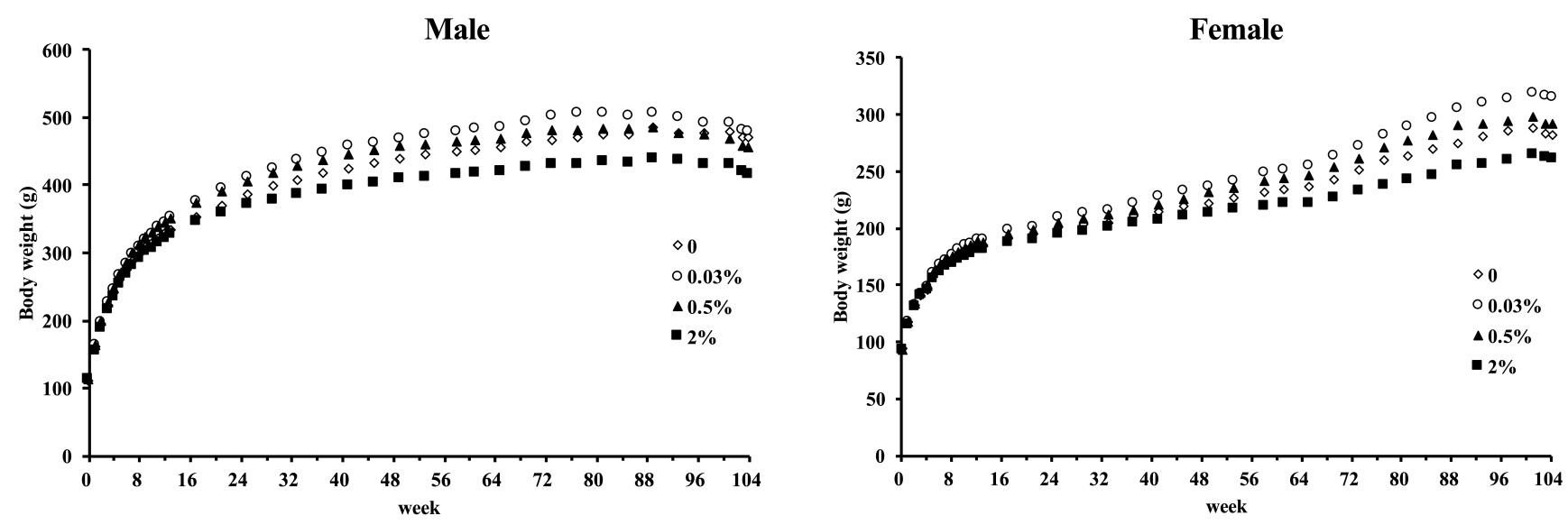
Fig. 2

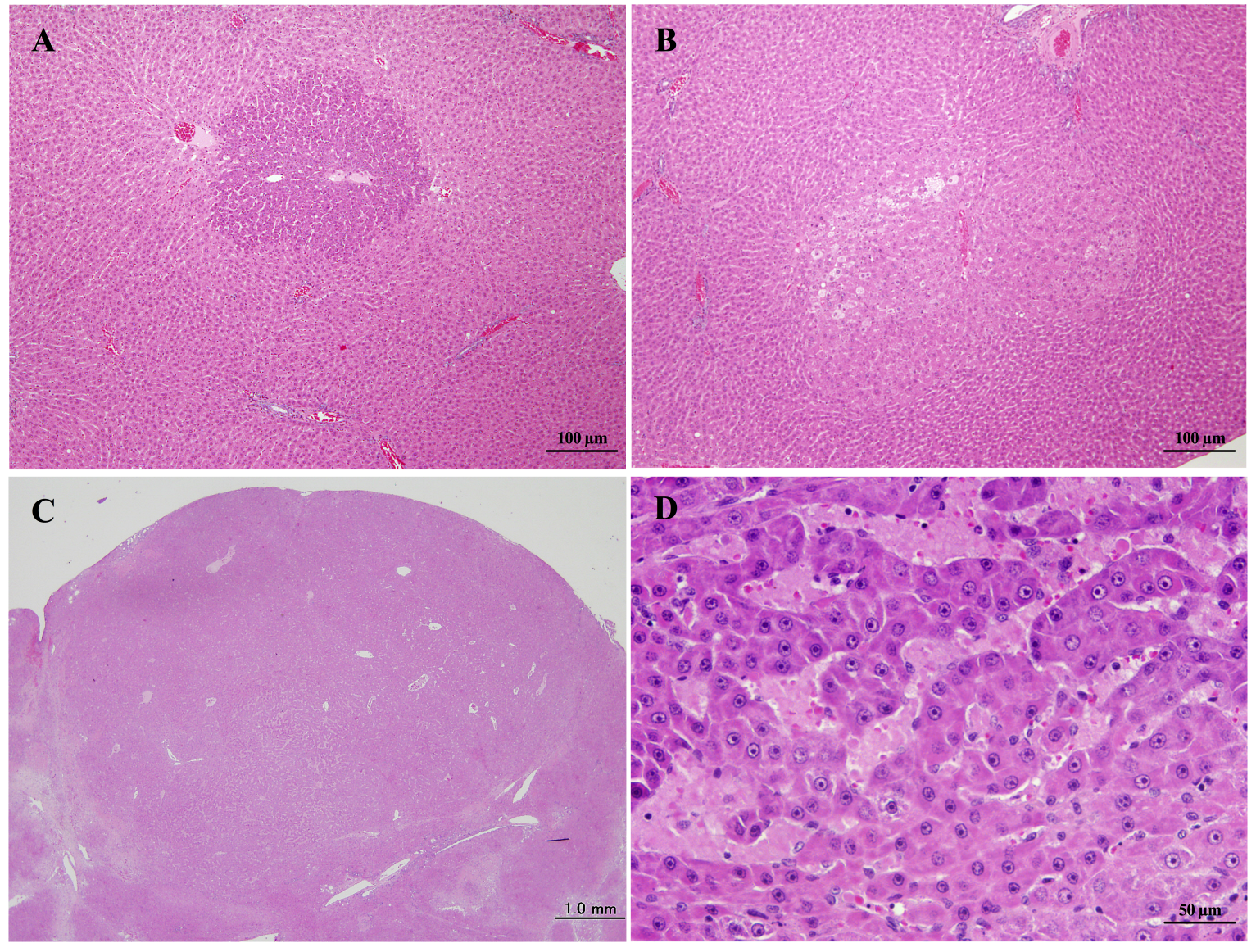


Fig. 3

A

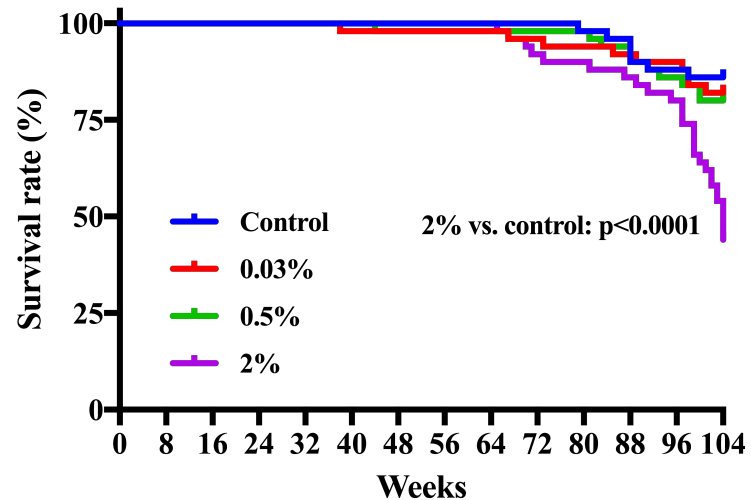

B

Female

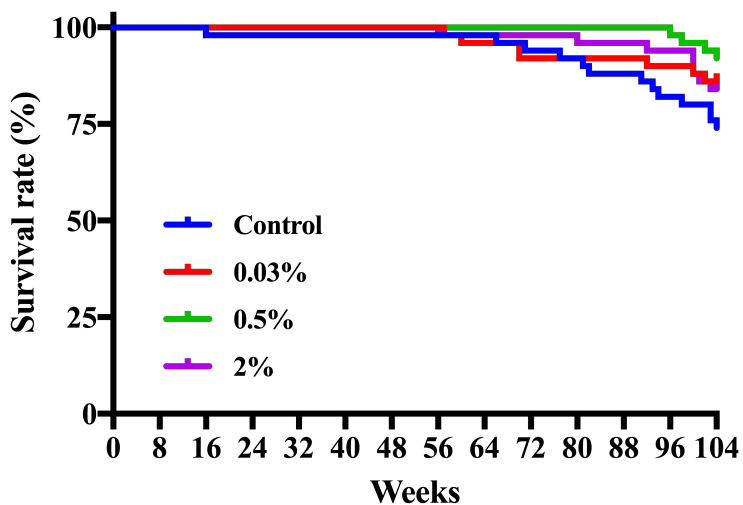


Fig. 4
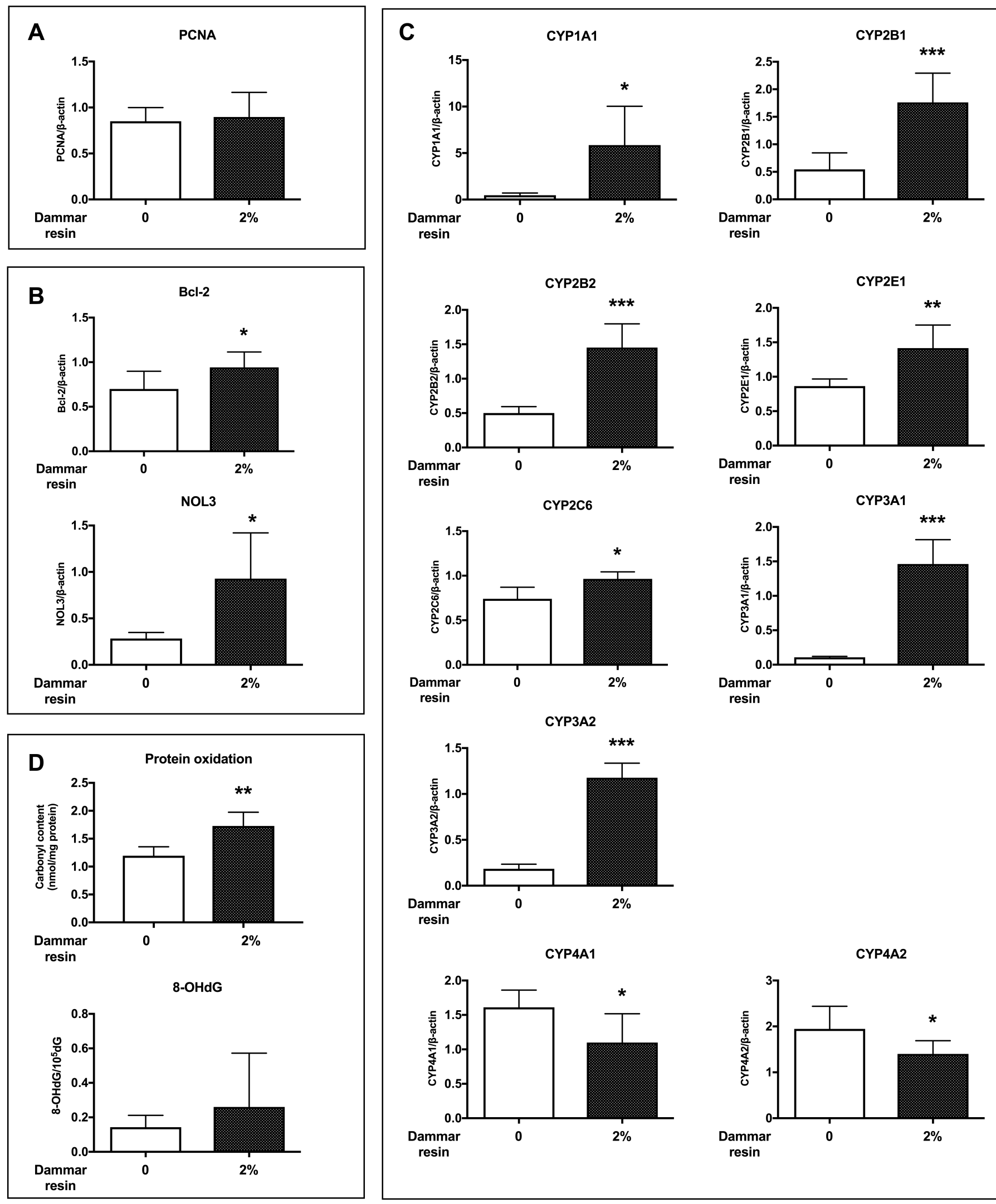


\section{Supplementary Table 1}

Average body weights (gram) of F344 rats in the 52-week chronic toxicity study

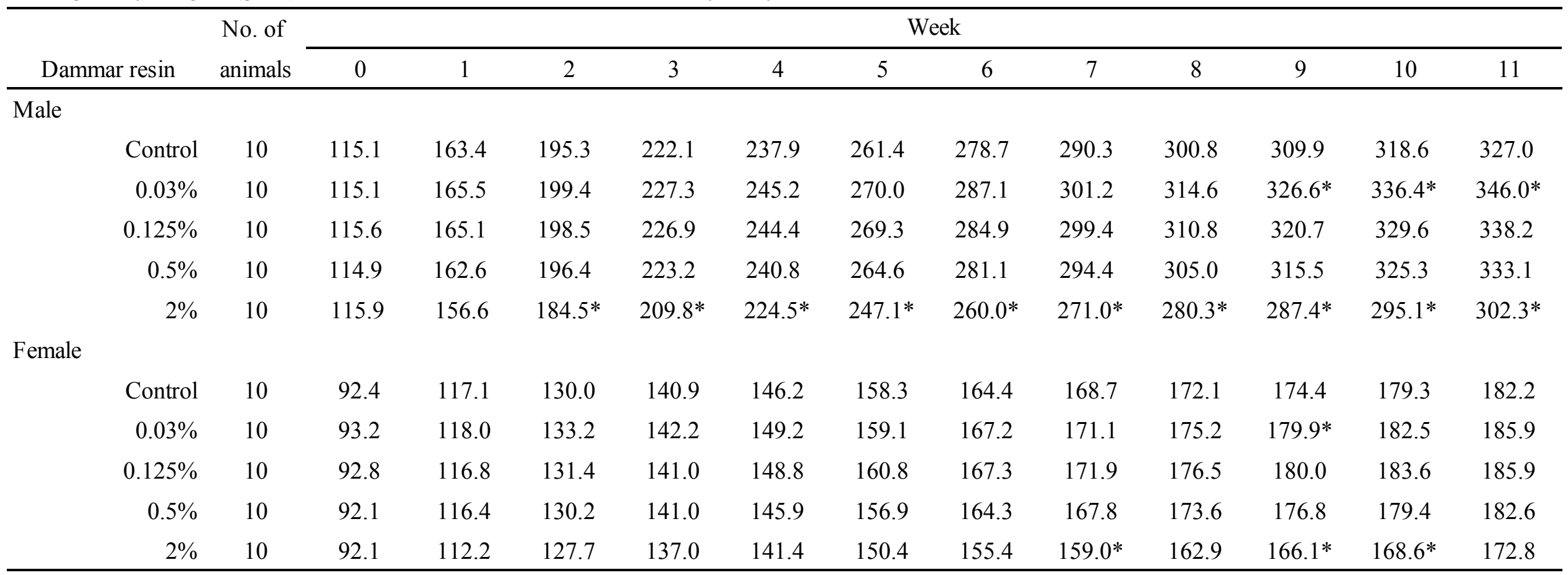

* Significantly different from the respective control group. 


\section{Supplementary Table 1 (contiuned)}

Average body weights (gram) of F344 rats in the 52-week chronic toxicity study

\begin{tabular}{|c|c|c|c|c|c|c|c|c|c|c|c|c|c|}
\hline \multirow[b]{2}{*}{ Dammar resin } & \multicolumn{13}{|c|}{ Week } \\
\hline & 12 & 13 & 17 & 21 & 25 & 29 & 33 & 37 & 41 & 45 & 49 & 51 & 52 \\
\hline \multicolumn{14}{|l|}{ Male } \\
\hline $0.03 \%$ & $354.7^{*}$ & $359.4^{*}$ & $384.6^{*}$ & $404.8^{*}$ & $420.4 *$ & $434.2 *$ & $443.8^{*}$ & $455.3 *$ & $463.0^{*}$ & $471.6^{*}$ & $479.7^{*}$ & $477.1^{*}$ & $477.4^{*}$ \\
\hline $0.125 \%$ & 346.2 & 349.2 & 374.1 & 392.3 & 408.4 & 419.0 & 426.9 & 436.4 & 445.7 & 454.3 & 462.6 & 460.5 & 460.5 \\
\hline \multicolumn{14}{|l|}{ Female } \\
\hline Control & 184.9 & 184.7 & 190.2 & 193.9 & 199.2 & 201.6 & 203.9 & 208.0 & 212.8 & 217.3 & 222.1 & 223.0 & 224.0 \\
\hline $0.03 \%$ & 188.7 & 188.6 & 197.2 & 202.7 & 208.4 & $210.6^{*}$ & 215.3 & $219.0^{*}$ & $227.3^{*}$ & 231.9 & $236.5^{*}$ & $238.4^{*}$ & $240.0^{*}$ \\
\hline $0.125 \%$ & 188.1 & 190.4 & 197.9 & 201.5 & 209.5 & $212.7^{*}$ & 217.2 & 223.8 & 226.2 & 232.7 & 237.8 & $237.9^{*}$ & 238.4 \\
\hline
\end{tabular}

* Significantly different from the respective control group. 


\section{Supplementary Table 2}

Weights of organs other than liver in the 52-week chronic toxicity study

\begin{tabular}{|c|c|c|c|c|c|}
\hline & & & Male & & \\
\hline Dammar resin & 0 & $0.03 \%$ & $0.125 \%$ & $0.5 \%$ & $2 \%$ \\
\hline No. of rats examined & 10 & 10 & 10 & 10 & 10 \\
\hline Kidneys & & & & & \\
\hline Absolute weight (g) & $2.36 \pm 0.28$ & $2.49 \pm 0.13$ & $2.36 \pm 0.13$ & $2.46 \pm 0.21$ & $2.43 \pm 0.24$ \\
\hline Relative weight (\%) & $0.53 \pm 0.07$ & $0.52 \pm 0.04$ & $0.51 \pm 0.01$ & $0.53 \pm 0.03$ & $0.61 \pm 0.06$ \\
\hline Spleen & & & & & \\
\hline Absolute weight (g) & $0.75 \pm 0.04$ & $0.78 \pm 0.06$ & $0.73 \pm 0.04$ & $0.75 \pm 0.04$ & $0.69 \pm 0.06^{*}$ \\
\hline Relative weight (\%) & $0.17 \pm 0.01$ & $0.16 \pm 0.01$ & $0.16 \pm 0.01$ & $0.16 \pm 0.01$ & $0.17 \pm 0.01$ \\
\hline Thymus & & & & & \\
\hline Absolute weight (mg) & $48 \pm 10$ & $50 \pm 12$ & $49 \pm 11$ & $49 \pm 9$ & $47 \pm 6$ \\
\hline Relative weight (\%) & $0.011 \pm 0.002$ & $0.011 \pm 0.002$ & $0.011 \pm 0.003$ & $0.011 \pm 0.002$ & $0.012 \pm 0.002$ \\
\hline Heart & & & & & \\
\hline Absolute weight (g) & $1.10 \pm 0.04$ & $1.18 \pm 0.07 *$ & $1.15 \pm 0.07$ & $1.17 \pm 0.08$ & $1.09 \pm 0.09$ \\
\hline Relative weight (\%) & $0.25 \pm 0.01$ & $0.25 \pm 0.01$ & $0.25 \pm 0.01$ & $0.25 \pm 0.02$ & $0.27 \pm 0.01 * * *$ \\
\hline Brain & & & & & \\
\hline Absolute weight (g) & $2.10 \pm 0.05$ & $2.15 \pm 0.08$ & $2.04 \pm 0.06$ & $2.09 \pm 0.04$ & $2.04 \pm 0.07$ \\
\hline Relative weight (\%) & $0.47 \pm 0.02$ & $0.45 \pm 0.02$ & $0.44 \pm 0.03$ & $0.46 \pm 0.03$ & $0.51 \pm 0.02 *$ \\
\hline Testis & & & & & \\
\hline Absolute weight (g) & $3.38 \pm 0.17$ & $3.53 \pm 0.46$ & $3.35 \pm 0.36$ & $3.35 \pm 0.25$ & $3.42 \pm 0.18$ \\
\hline Relative weight (\%) & $0.75 \pm 0.04$ & $0.74 \pm 0.11$ & $0.73 \pm 0.08$ & $0.73 \pm 0.05$ & $0.85 \pm 0.05 *$ \\
\hline & & & Female & & \\
\hline Dammar resin & 0 & $0.03 \%$ & $0.125 \%$ & $0.5 \%$ & $2 \%$ \\
\hline No. of rats examined & 10 & 10 & 10 & 10 & 10 \\
\hline Kidneys & & & & & \\
\hline Absolute weight (g) & $1.48 \pm 0.07$ & $1.46 \pm 0.10$ & $1.39 \pm 0.10$ & $1.43 \pm 0.13$ & $1.44 \pm 0.06$ \\
\hline Relative weight (\%) & $0.66 \pm 0.05$ & $0.61 \pm 0.04 *$ & $0.58 \pm 0.04 * * *$ & $0.61 \pm 0.03 *$ & $0.70 \pm 0.03$ \\
\hline Spleen & & & & & \\
\hline Absolute weight (g) & $0.43 \pm 0.04$ & $0.44 \pm 0.04$ & $0.42 \pm 0.04$ & $0.42 \pm 0.04$ & $0.37 \pm 0.04 * *$ \\
\hline Relative weight (\%) & $0.19 \pm 0.02$ & $0.18 \pm 0.02$ & $0.18 \pm 0.01$ & $0.18 \pm 0.01$ & $0.18 \pm 0.02$ \\
\hline Thymus & & & & & \\
\hline Absolute weight (mg) & $53 \pm 10$ & $55 \pm 7$ & $49 \pm 15$ & $47 \pm 12$ & $54 \pm 8$ \\
\hline Relative weight (\%) & $0.024 \pm 0.004$ & $0.023 \pm 0.003$ & $0.020 \pm 0.006$ & $0.020 \pm 0.005$ & $0.026 \pm 0.004$ \\
\hline Heart & & & & & \\
\hline Absolute weight (g) & $0.70 \pm 0.04$ & $0.71 \pm 0.04$ & $0.69 \pm 0.05$ & $0.73 \pm 0.06$ & $0.65 \pm 0.21$ \\
\hline Relative weight (\%) & $0.31 \pm 0.01$ & $0.30 \pm 0.02$ & $0.29 \pm 0.01 *$ & $0.31 \pm 0.03$ & $0.31 \pm 0.10$ \\
\hline Brain & & & & & \\
\hline Absolute weight (g) & $1.88 \pm 0.06$ & $1.86 \pm 0.04$ & $1.88 \pm 0.04$ & $1.83 \pm 0.09$ & $1.66 \pm 0.40$ \\
\hline Relative weight (\%) & $0.84 \pm 0.04$ & $0.78 \pm 0.03 *$ & $0.79 \pm 0.05$ & $0.79 \pm 0.08$ & $0.80 \pm 0.21$ \\
\hline
\end{tabular}

Significantly different from the respective control at $* \mathrm{p}<0.05 ; * * \mathrm{p}<0.01 ; * * \mathrm{p}<0.001$, respectively. 


\section{Supplementary Table 3}

Average body weights (gram) in the 104-week carcinogenicity study

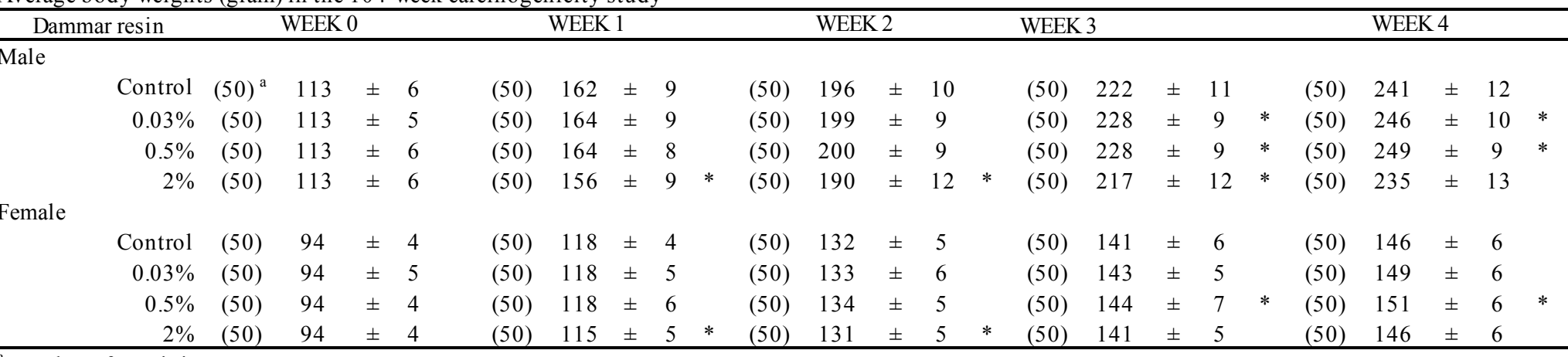

${ }^{a}$ Number of surviving rat.

* Significantly different from coresponding control group.

Supplementary Table 3 (contiuned)

Average body weights (gram) in the 104-week carcinogenicity study

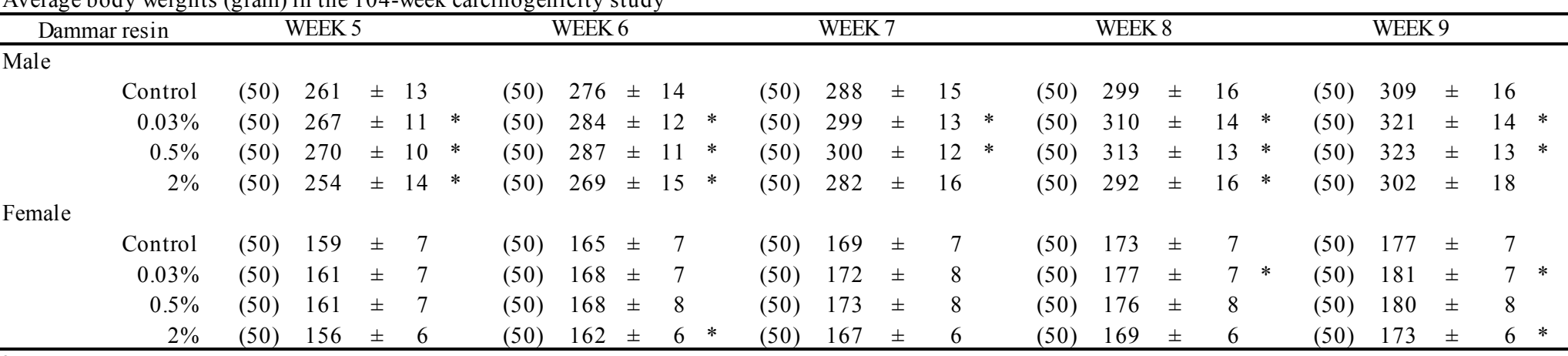

${ }^{\mathrm{a}}$ Number of surviving rat

* Significantly different from coresponding control group. 
Supplementary Table 3 (contiuned)

Average body weights (gram) in the 104-week carcinogenicity study

\begin{tabular}{|c|c|c|c|c|c|c|c|c|c|c|c|c|c|c|c|c|c|c|c|c|c|c|c|c|c|c|}
\hline \multicolumn{2}{|c|}{ Dammar resin } & \multicolumn{5}{|c|}{ WEEK 10} & \multicolumn{4}{|c|}{ WEEK 11} & \multicolumn{6}{|c|}{ WEEK 12} & \multicolumn{4}{|c|}{ WEEK 13} & \multicolumn{6}{|c|}{ WEEK 17} \\
\hline \multicolumn{27}{|l|}{ Male } \\
\hline & Control & $(50)^{\mathrm{a}}$ & 316 & \pm & 17 & & $(50)$ & 323 & \pm & 17 & & $(50)$ & 330 & \pm & 18 & & $(50)$ & 335 & \pm & 19 & & $(50)$ & 355 & \pm & 20 & \\
\hline & $0.03 \%$ & $(50)$ & 329 & \pm & 15 & * & $(50)$ & 338 & \pm & 15 & $*$ & $(50)$ & 346 & \pm & 16 & $*$ & $(50)$ & 353 & \pm & 16 & $*$ & $(50)$ & 377 & \pm & 18 & $*$ \\
\hline & $0.5 \%$ & $(50)$ & 331 & \pm & 14 & * & $(50)$ & 339 & \pm & 14 & $*$ & $(50)$ & 345 & \pm & 15 & $*$ & $(50)$ & 351 & \pm & 15 & $*$ & $(50)$ & 374 & \pm & 16 & $*$ \\
\hline & $2 \%$ & (50) & 308 & \pm & 17 & * & $(50)$ & 315 & \pm & 18 & $*$ & $(50)$ & 321 & \pm & 18 & $*$ & (50) & 328 & \pm & 19 & & $(50)$ & 347 & \pm & 20 & \\
\hline \multicolumn{27}{|l|}{ Female } \\
\hline & Control & (50) & 181 & \pm & 7 & & $(50)$ & 184 & \pm & 8 & & $(50)$ & 186 & \pm & 7 & & $(50)$ & 185 & \pm & 7 & & (49) & 192 & \pm & 7 & \\
\hline & $0.03 \%$ & (50) & 185 & \pm & 8 & * & $(50)$ & 187 & \pm & 7 & * & $(50)$ & 190 & \pm & 7 & $*$ & $(50)$ & 191 & \pm & 7 & $*$ & $(50)$ & 199 & \pm & 7 & * \\
\hline & $0.5 \%$ & (50) & 183 & \pm & 9 & & (50) & 186 & \pm & 9 & & $(50)$ & 189 & \pm & 8 & & (50) & 188 & \pm & 8 & & (50) & 195 & \pm & 9 & \\
\hline & $2 \%$ & (50) & 176 & \pm & 6 & * & (50) & 179 & \pm & 6 & $*$ & $(50)$ & 182 & \pm & 6 & $*$ & (50) & 182 & \pm & 6 & $*$ & (50) & 188 & \pm & 6 & * \\
\hline
\end{tabular}

${ }^{\mathrm{a}}$ Number of surviving rat

* Significantly different from coresponding control group.

Supplementary Table 3 (contiuned)

Average body weights (gram) in the 104-week carcinogenicity study

\begin{tabular}{|c|c|c|c|c|c|c|c|c|c|c|c|c|c|c|c|c|c|c|c|c|c|c|c|c|c|c|}
\hline \multicolumn{2}{|c|}{ Dammar resin } & \multicolumn{4}{|c|}{ WEEK 21} & & \multicolumn{4}{|c|}{ WEEK 25} & & \multicolumn{4}{|c|}{ WEEK 29} & \multicolumn{3}{|c|}{ WEEK 33} & \multicolumn{8}{|c|}{ WEEK 37} \\
\hline Male & & & & & & & & & & & & & & & & & & & & & & & & & & \\
\hline & Control & (50) & 371 & \pm & 20 & & $(50)$ & 388 & \pm & 21 & & (50) & 400 & \pm & 21 & & $(50)$ & 409 & \pm & 22 & & (50) & 419 & \pm & 21 & \\
\hline & $0.03 \%$ & (50) & 396 & \pm & 20 & * & $(50)$ & 413 & \pm & 21 & * & $(50)$ & 426 & \pm & 22 & $*$ & (50) & 438 & \pm & 22 & $*$ & (49) & 449 & \pm & 24 & * \\
\hline & $0.5 \%$ & $(50)$ & 391 & \pm & 18 & * & $(50)$ & 406 & \pm & 17 & * & (50) & 419 & \pm & 19 & * & (50) & 429 & \pm & 19 & * & $(50)$ & 438 & \pm & 19 & * \\
\hline & $2 \%$ & $(50)$ & 360 & \pm & 21 & * & $(50)$ & 372 & \pm & 20 & $*$ & $(50)$ & 378 & \pm & 21 & $*$ & $(50)$ & 387 & \pm & 21 & $*$ & (50) & 393 & \pm & 21 & * \\
\hline \multicolumn{27}{|l|}{ Female } \\
\hline & Control & (49) & 195 & \pm & 8 & & (49) & 201 & \pm & 9 & & (49) & 204 & \pm & 9 & & (49) & 205 & \pm & 8 & & (49) & 211 & \pm & 9 & \\
\hline & $0.03 \%$ & $(50)$ & 202 & \pm & 8 & * & $(50)$ & 210 & \pm & 8 & * & $(50)$ & 214 & \pm & 9 & $*$ & $(50)$ & 216 & \pm & 10 & $*$ & $(50)$ & 222 & \pm & 10 & * \\
\hline & $0.5 \%$ & $(50)$ & 198 & \pm & 9 & & $(50)$ & 204 & \pm & 9 & & (50) & 208 & \pm & 9 & $*$ & $(50)$ & 212 & \pm & 10 & $*$ & $(50)$ & 216 & \pm & 10 & * \\
\hline & $2 \%$ & $(50)$ & 190 & \pm & 6 & $*$ & $(50)$ & 195 & \pm & 7 & $*$ & $(50)$ & 198 & \pm & 7 & $*$ & $(50)$ & 201 & \pm & 7 & & $(50)$ & 205 & \pm & 8 & $*$ \\
\hline
\end{tabular}

${ }^{a}$ Number of surviving rat.

* Significantly different from coresponding control group. 
Supplementary Table 3 (contiuned)

Average body weights (gram) in the 104-week carcinogenicity study

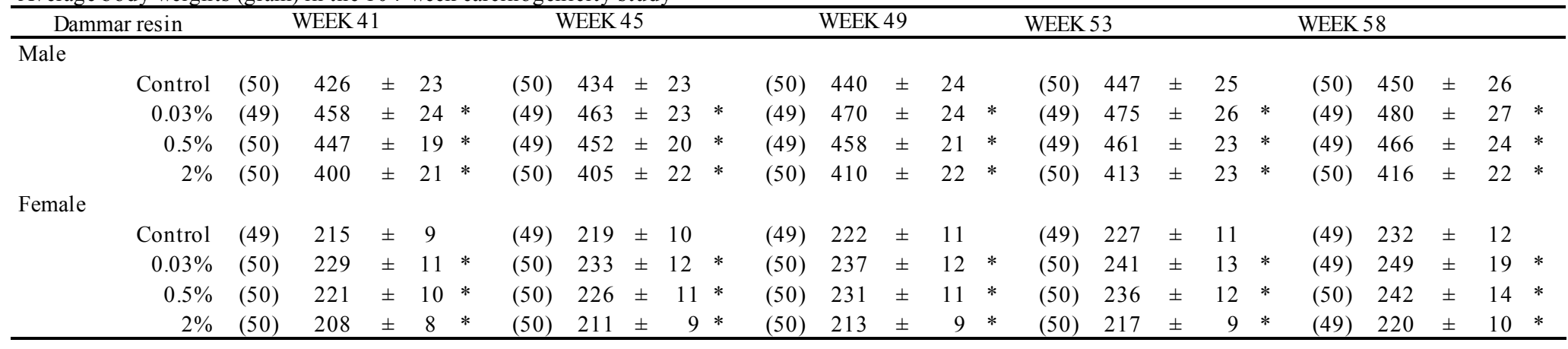

\begin{tabular}{|c|c|c|c|c|c|c|c|c|c|c|c|c|c|c|c|c|c|c|c|c|c|c|c|c|c|c|}
\hline \multirow[b]{2}{*}{ Male } & \multicolumn{5}{|c|}{ WEEK 61} & \multicolumn{3}{|c|}{ WEEK 65} & \multicolumn{6}{|c|}{ WEEK 69} & \multicolumn{5}{|c|}{ WEEK 73} & \multicolumn{5}{|c|}{ WEEK 77} & & \\
\hline & & & & & & & & & & & & & & & & & & & & & & & & & & \\
\hline & Control & $(50)$ & 453 & \pm & 27 & & $(50)$ & 457 & \pm & 26 & & $(50)$ & 465 & \pm & 28 & & $(50)$ & 468 & \pm & 28 & & $(50)$ & 472 & \pm & 29 & \\
\hline & $0.03 \%$ & (49) & 484 & \pm & 28 & $*$ & (49) & 486 & \pm & 34 & $*$ & $(48)$ & 495 & \pm & 30 & $*$ & (47) & 504 & \pm & 32 & $*$ & (47) & 506 & \pm & 31 & * \\
\hline & $0.5 \%$ & (49) & 468 & \pm & 25 & * & (49) & 470 & \pm & 26 & & (49) & 477 & \pm & 28 & & (49) & 482 & \pm & 29 & * & (49) & 483 & \pm & 28 & \\
\hline & $2 \%$ & $(50)$ & 419 & \pm & 23 & $*$ & (49) & 421 & \pm & 25 & * & (47) & 427 & \pm & 22 & $*$ & (45) & 431 & \pm & 23 & $*$ & (45) & 433 & \pm & 24 & * \\
\hline \multicolumn{27}{|l|}{ Female } \\
\hline & Control & (49) & 234 & \pm & 13 & & (48) & 237 & \pm & 15 & & $(48)$ & 244 & \pm & 18 & & (47) & 251 & \pm & 20 & & (46) & 260 & \pm & 21 & \\
\hline & $0.03 \%$ & (48) & 252 & \pm & 19 & * & (48) & 255 & \pm & 22 & * & $(46)$ & 264 & \pm & 22 & * & $(46)$ & 273 & \pm & 24 & * & (46) & 283 & \pm & 25 & * \\
\hline & $0.5 \%$ & (50) & 244 & \pm & 16 & $*$ & $(50)$ & 247 & \pm & 17 & $*$ & $(50)$ & 254 & \pm & 18 & $*$ & $(50)$ & 262 & \pm & 20 & $*$ & $(50)$ & 271 & \pm & 22 & * \\
\hline & $2 \%$ & (49) & 222 & \pm & 10 & * & (49) & 223 & \pm & 11 & * & (49) & 228 & \pm & 12 & * & (49) & 233 & \pm & 14 & $*$ & (49) & 238 & \pm & 15 & * \\
\hline
\end{tabular}

${ }^{a}$ Number of surviving rat.

* Significantly different from coresponding control group. 
Supplementary Table 3 (contiuned)

Average body weights (gram) in the 104-week carcinogenicity study

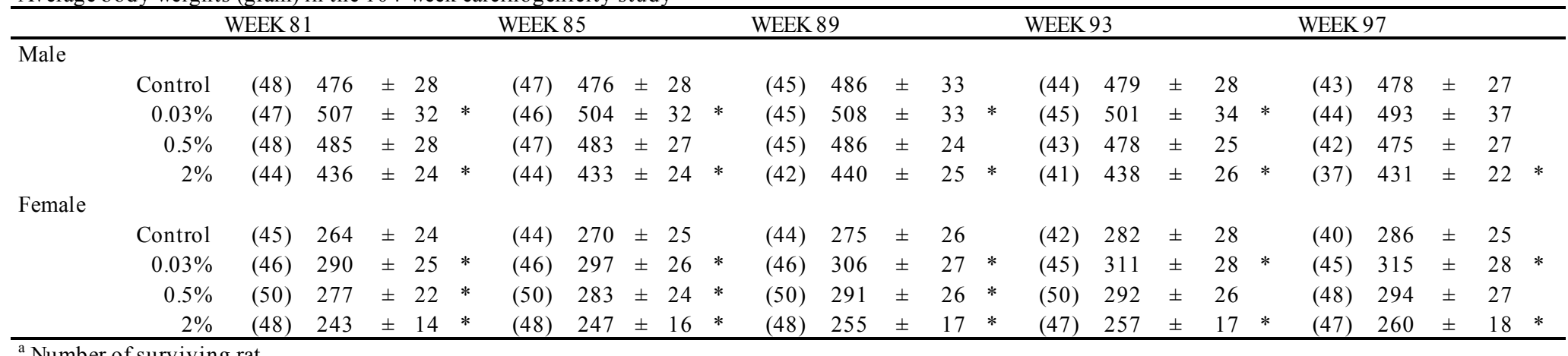

${ }^{\mathrm{a}}$ Number of surviving rat.

* Significantly different from coresponding control group.

Supplementary Table 3 (contiuned)

Average body weights (gram) in the 104-week carcinogenicity study

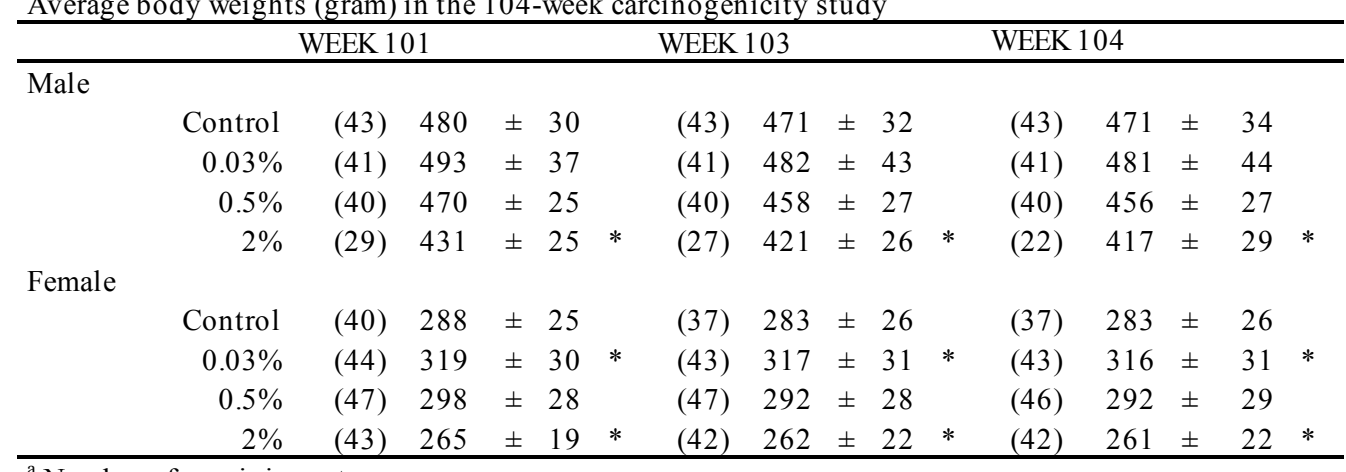

${ }^{\mathrm{a}}$ Number of surviving rat.

* Significantly different from coresponding control group. 
Supplementary Table 4

Weights of organs other than liver in the 104-week carcinogenicity study

\begin{tabular}{|c|c|c|c|c|c|c|c|c|}
\hline \multirow[b]{2}{*}{ Dammar resin } & \multicolumn{4}{|c|}{ Male } & \multicolumn{4}{|c|}{ Female } \\
\hline & 0 & $0.03 \%$ & $0.5 \%$ & $2 \%$ & 0 & $0.03 \%$ & $0.5 \%$ & $2 \%$ \\
\hline No. of rats examined ${ }^{\mathrm{a}}$ & 43 & 41 & 40 & 22 & 37 & 43 & 46 & 42 \\
\hline \multicolumn{9}{|l|}{ Kidney } \\
\hline Absolute weight (g) & $2.75 \pm 0.29$ & $2.87 \pm 0.19 * *$ & $2.90 \pm 0.28 * *$ & $2.78 \pm 0.11$ & $1.76 \pm 0.17$ & $1.81 \pm 0.11$ & $1.85 \pm 0.21 *$ & $1.78 \pm 0.12$ \\
\hline Relative weight (\%) & $0.59 \pm 0.08$ & $0.60 \pm 0.07$ & $0.64 \pm 0.07 * * *$ & $0.67 \pm 0.04 * * *$ & $0.63 \pm 0.09$ & $0.58 \pm 0.05^{*}$ & $0.64 \pm 0.11$ & $0.68 \pm 0.06^{* * *}$ \\
\hline \multicolumn{9}{|l|}{ Spleen } \\
\hline Absolute weight (g) & $1.07 \pm 0.18$ & $1.36 \pm 0.97$ & $1.38 \pm 1.77$ & $1.44 \pm 1.48^{* *}$ & $0.72 \pm 0.53$ & $0.59 \pm 0.18$ & $0.76 \pm 0.96$ & $0.73 \pm 0.93 *$ \\
\hline Relative weight (\%) & $0.2 \pm 0.0$ & $0.3 \pm 0.3$ & $0.3 \pm 0.4$ & $0.3 \pm 0.3$ & $0.3 \pm 0.2$ & $0.2 \pm 0.1$ & $0.3 \pm 0.3$ & $0.3 \pm 0.4$ \\
\hline \multicolumn{9}{|l|}{ Heart } \\
\hline Absolute weight (g) & $1.23 \pm 0.15$ & $1.26 \pm 0.13$ & $1.25 \pm 0.09$ & $1.19 \pm 0.06$ & $0.80 \pm 0.06$ & $0.84 \pm 0.06^{* *}$ & $0.84 \pm 0.06^{*}$ & $0.81 \pm 0.05$ \\
\hline Relative weight (\%) & $0.26 \pm 0.03$ & $0.26 \pm 0.03$ & $0.27 \pm 0.03$ & $0.29 \pm 0.03 * *$ & $0.29 \pm 0.03$ & $0.27 \pm 0.03 *$ & $0.29 \pm 0.03$ & $0.31 \pm 0.02 * * *$ \\
\hline \multicolumn{9}{|l|}{ Brain } \\
\hline Absolute weight (g) & $2.12 \pm 0.06$ & $2.13 \pm 0.06$ & $2.10 \pm 0.06$ & $2.09 \pm 0.05$ & $1.90 \pm 0.06$ & $1.92 \pm 0.05$ & $1.91 \pm 0.06$ & $1.90 \pm 0.06$ \\
\hline Relative weight (\%) & $0.45 \pm 0.03$ & $0.45 \pm 0.04$ & $0.46 \pm 0.03$ & $0.50 \pm 0.03 * * *$ & $0.68 \pm 0.07$ & $0.62 \pm 0.06 * * *$ & $0.66 \pm 0.08$ & $0.73 \pm 0.06 * *$ \\
\hline \multicolumn{9}{|l|}{ Thymus } \\
\hline Absolute weight (g) & $0.07 \pm 0.04$ & $0.07 \pm 0.05$ & $0.06 \pm 0.03$ & $0.07 \pm 0.03$ & $0.05 \pm 0.02$ & $0.05 \pm 0.02$ & $0.05 \pm 0.02$ & $0.05 \pm 0.02$ \\
\hline Relative weight (\%) & $0.45 \pm 0.03$ & $0.45 \pm 0.04$ & $0.46 \pm 0.03$ & $0.50 \pm 0.03$ & $0.68 \pm 0.07$ & $0.62 \pm 0.06$ & $0.66 \pm 0.08$ & $0.73 \pm 0.06$ \\
\hline \multicolumn{9}{|l|}{ Testis } \\
\hline Absolute weight (g) & $3.3 \pm 1.0$ & $3.4 \pm 0.9$ & $3.5 \pm 0.9$ & $3.4 \pm 0.7$ & & & & \\
\hline Relative weight (\%) & $0.8 \pm 0.2$ & $0.7 \pm 0.2$ & $0.7 \pm 0.2$ & $0.9 \pm 0.2$ & & & & \\
\hline
\end{tabular}

a: No. of rats surviving to the end of the experiment.

Significantly different from the respective control at $* \mathrm{p}<0.05 ; * * \mathrm{p}<0.01 ; * * * \mathrm{p}<0.001$, respectively. 


\section{Supplementary Fig. 1}
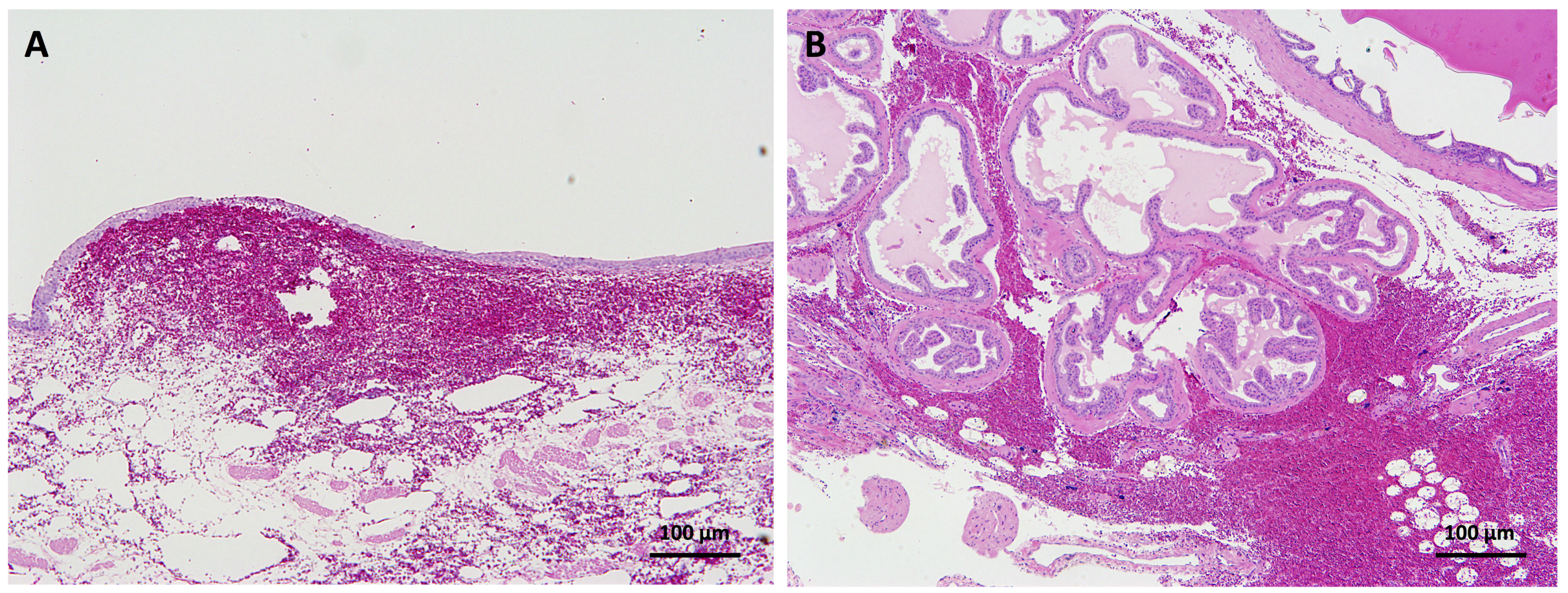